\title{
Functional microRNA targetome undergoes degeneration-induced shift in the retina
}

\author{
Joshua A. Chu-Tan ${ }^{1,2+}$, Adrian V. Cioanca ${ }^{1 \dagger}$, Zhi-Ping Feng ${ }^{3}$, Yvette Wooff ${ }^{1,2}$, Ulrike Schumann ${ }^{1}$, \\ Riemke Aggio-Bruce ${ }^{1,2}$, Hardip Patel ${ }^{3}$, Matt Rutar ${ }^{4,5}$, Katherine Hannan ${ }^{6}$, Konstantin Panov ${ }^{7}$, Jan Provis ${ }^{1,2}$ and \\ Riccardo Natoli ${ }^{1,2^{*}}$ (D)
}

\begin{abstract}
Background: MicroRNA (miRNA) play a significant role in the pathogenesis of complex neurodegenerative diseases including age-related macular degeneration (AMD), acting as post-transcriptional gene suppressors through their association with argonaute 2 (AGO2) - a key member of the RNA Induced Silencing Complex (RISC). Identifying the retinal miRNA/mRNA interactions in health and disease will provide important insight into the key pathways miRNA regulate in disease pathogenesis and may lead to potential therapeutic targets to mediate retinal degeneration.

Methods: To identify the active miRnome targetome interactions in the healthy and degenerating retina, AGO2 HITS-CLIP was performed using a rodent model of photoreceptor degeneration. Analysis of publicly available singlecell RNA sequencing (scRNAseq) data was performed to identify the cellular location of AGO2 and key members of the microRNA targetome in the retina. AGO2 findings were verified by in situ hybridization (RNA) and immunohistochemistry (protein).

Results: Analysis revealed a similar miRnome between healthy and damaged retinas, however, a shift in the active targetome was observed with an enrichment of miRNA involvement in inflammatory pathways. This shift was further demonstrated by a change in the seed binding regions of miR-124-3p, the most abundant retinal AGO2bound miRNA, and has known roles in regulating retinal inflammation. Additionally, photoreceptor cluster miR-183/ 96/182 were all among the most highly abundant miRNA bound to AGO2. Following damage, AGO2 expression was localized to the inner retinal layers and more in the OLM than in healthy retinas, indicating a locational miRNA response to retinal damage.
\end{abstract}

Conclusions: This study provides important insight into the alteration of miRNA regulatory activity that occurs as a response to retinal degeneration and explores the miRNA-mRNA targetome as a consequence of retinal degenerations. Further characterisation of these miRNA/mRNA interactions in the context of the degenerating retina may provide an important insight into the active role these miRNA may play in diseases such as AMD.

Keywords: Retina, microRNA, mRNA, Retinal degeneration, Argonaute, HITS-CLIP, Transcriptome, Inflammation

\footnotetext{
* Correspondence: riccardo.natoli@anu.edu.au

${ }^{\dagger}$ Joshua A. Chu-Tan and Adrian V. Cioanca share co-first authorship.

${ }^{1}$ Eccles Institute of Neuroscience, The John Curtin School of Medical

Research, College of Health and Medicine, The Australian National University,

Acton, Canberra, ACT 2601, Australia

${ }^{2}$ The Australian National University Medical School, College of Health and

Medicine, Canberra, ACT 2601, Australia

Full list of author information is available at the end of the article
}

\section{$\triangle B M C$}

C C The Author(s). 2021 Open Access This article is licensed under a Creative Commons Attribution 4.0 International License, which permits use, sharing, adaptation, distribution and reproduction in any medium or format, as long as you give appropriate credit to the original author(s) and the source, provide a link to the Creative Commons licence, and indicate if changes were made. The images or other third party material in this article are included in the article's Creative Commons licence, unless indicated otherwise in a credit line to the material. If material is not included in the article's Creative Commons licence and your intended use is not permitted by statutory regulation or exceeds the permitted use, you will need to obtain permission directly from the copyright holder. To view a copy of this licence, visit http://creativecommons.org/licenses/by/4.0/. The Creative Commons Public Domain Dedication waiver (http://creativecommons.org/publicdomain/zero/1.0/) applies to the data made available in this article, unless otherwise stated in a credit line to the data. 


\section{Background}

MicroRNA (miRNA) are a class of small endogenous non-coding RNAs that act as post-transcriptional gene repressors, and have been implicated in the control of cellular and tissue homeostasis, development and biological pathway regulation [1]. miRNAs are incorporated into argonaute (AGO) proteins which then assemble to be part of the RNA-induced silencing complex (RISC) [2-7]. Once incorporated into RISC, miRNAs guide binding of AGO to the 3' untranslated (3' UTR) of the mRNA target(s) through recognition of the miRNA seed region (typically 6-8 nucleotides long, commonly referred to as 6-mer, 7-mer and 8-mer seed region) [8]. This process results in post-transcriptional gene silencing through translational repression or mRNA degradation $[9,10]$.

A single miRNA has the ability to target hundreds of mRNAs, often all working in similar biological pathways, thus allowing for the mapping and identification of specific "miRNA networks" [11]. Due to their selective targeting ability, miRNAs have emerged as key orchestrators of the mammalian transcriptome. As such, their dysregulation has been implicated in the pathogenesis of multiple inflammatory diseases, cancers, neurological disorders as well as retinal degenerative diseases including age-related macular degeneration (AMD) [12-16], a disorder that specifically affects the central vision due to progressive damage to the light-sensing photoreceptor cells in the macular region. Retinal degenerations such as AMD have complex and multi-faceted etiology, with causal links to the pathogenesis of how retinal degeneration develops in AMD remaining elusive [17-22].

Multiple miRNAs have been postulated to play a role in both retinal homeostasis and pathogenesis including in AMD [14, 15, 23-30]. An important retinal miRNA subset is the "photoreceptor cluster," miR-182/96/183, which together have been established as key in the development of the light-sensing photoreceptors of the retina. Another example is miR-124, which has been heavily studied in the central nervous system (CNS) and is the most highly abundant miRNA in the brain [3134]. In the retina, miR-124 is expressed in the photoreceptor neurons and has been documented to play an anti-inflammatory role in neuronal tissue with reduced miR-124 in the retinal microglia cells leading to an increase in the activation of these cells [14]. However, a comprehensive list of their targets has, currently, only been largely predicted and elucidation of their functional targets would provide crucial insight into their specific roles in the retina during health and disease.

In order to further advance our understanding of the molecular roles that miRNAs play in the normal and degenerating retina, we performed high-throughput sequencing following cross-linking immunoprecipitation (HITS-CLIP) [35] in the retina. This enables high confidence validation of miRNA targets, which has historically been problematic when based on in silico predictions [36-40]. AGO2, as a core component of the RISC complex, has been implicated in the biogenesis and maturation of miRNAs, in addition to directly binding mature miRNAs for mRNA target repression [41]. Importantly, AGO2 CLIP enables the identification of only RISC-complexed, biologically functional miRNAs and their resultant targetome [36-40]. This is afforded from crosslinking RNA binding proteins (AGO2) with miRNAs and mRNAs, immunoprecipitating AGO2 proteins and subsequently sequencing the associated RNA.

In the study presented here, we revealed that the majority of the retinal AGO2-bound miRnome was comprised of only a small miRNA subset, with miR-124-3p being highly represented. While the retinal AGO2bound miRnome did not differ in expression between healthy and damaged retinas, we identified an altered AGO2-bound mRNA profile, representing a shift in the targetome following retinal damage. This was associated with a dynamic change in seed region binding of miR124-3p. Finally, we showed that upon retinal damage AGO2 accumulated in the inner retinal layers and colocalized more strongly with the Müller glia, which suggests a major shift in miRNA activity in these cells. Together these results provide mechanistic insight into the effects of degeneration on the miRNA-mRNA regulatory networks in the retina.

\section{Methods}

\section{Animal experiments}

All animal experiments were conducted in accordance with the ARVO Statement for Use of Animals in Ophthalmic and Vision Research and with approval from the ANU Animal Experimentation Ethics Committee (Ethics ID: A2014/56). C57BL/6 J mice aged between P60-80 and devoid of the $\mathrm{RPE}^{65450 \mathrm{Met}}$ and $\mathrm{Crbl}^{\mathrm{rd} 8}$ mutations were used for experiments. Mice were born and reared in individually vented cages in cyclic dim light conditions $(12 \mathrm{~h}$ at $5 \mathrm{~lx}, 12 \mathrm{~h}$ at $0 \mathrm{~lx})$. Müller glia reporter animals were derived by crossing the PDGFRa-Cre transgenic mice (strain ID: \#013148; The Jackson Laboratory) with a Gt (ROSA)26Sortm14 floxed RFP reporter strain (ID: 007914, The Jackson Laboratory) maintained on the C57BL/6 J background and screened for the RPE ${ }^{65450 M e t}$ and $\mathrm{Crb1}^{\text {rd8 }}$ mutations.

\section{Photo-oxidative damage}

Photo-oxidative damage (PD) was used to mimic the pathogenesis of atrophic AMD in mice as described previously [42]. Animals were placed into perspex boxes coated with a reflective interior surface and exposed to 
$100 \mathrm{~K}$ lux white light from light-emitting diodes (LED). Exposure was continuous for a period of 5 days with food and water ad libitum. Animals were administered pupil dilator (Minims ${ }^{\circ}$ atropine sulphate $1 \% \mathrm{w} / \mathrm{v}$; Bausch and Lomb) to both eyes twice a day during the course of the damage paradigm. Dim-reared (dim) animals maintained in normal cyclic light rearing conditions were used as control.

\section{Tissue collection and preparation}

Both dim and PD animals were culled by $\mathrm{CO}_{2}$ exposure. For retinal extraction, eyes were dissected using an ophthalmic knife, cut across the anterior surface. The lens was removed, the retina extracted using curved forceps and immediately immersed in RNAlater (Thermo Fisher Scientific, Waltham, MA) for overnight storage at $-4{ }^{\circ} \mathrm{C}$ then transferred to $-80^{\circ} \mathrm{C}$ until needed. Six retinas from three animals were pooled for a single biological replicate, $n=4$ biological replicate samples for both control and damaged retina were used for experimentation.

\section{Total RNA isolation from retinas}

Total RNA was purified by acid phenol/chloroform lysis followed by the enrichment and purification of the aqueous phase for long and short RNA using the mirVana ${ }^{\text {Tx }}$ Total RNA Isolation Kit (Thermo Fisher Scientific) according to manufacturer's instructions. This yielded two samples: 1) small RNAs isolated from AGO2:miRNA and AGO2:miRNA:mRNA complexes; 2) mRNA isolated from AGO2:miRNA:mRNA complexes. RNA concentration was determined using a Qubit 4 Fluorometer (Thermo Fisher Scientific) and RNA quality was measured on a 2100 Bioanalyser using an RNA 6000 Nano Assay (Agilent Technologies, Santa Clara, CA). Only samples with an RNA integrity number (RIN) greater than 9.0 were carried forward to library preparation and high-throughput sequencing.

\section{AGO2 HITS-CLIP}

Retinas were diced to a fine suspension in ice-cold PBS and then UV irradiated three times at $400 \mathrm{~mJ} / \mathrm{cm}^{2}$ (Stratalinker) whilst swirling suspension between each irradiation to keep cold and ensure maximal surface exposure. Cross-linked tissue was either used directly or flashfrozen in liquid $\mathrm{N}_{2}$ and stored at $-80^{\circ} \mathrm{C}$. AGO2 HITSCLIP was performed using a protocol adapted from Moore et al., 2014 [43]. All buffers were made fresh based on this aforementioned protocol [43]. Antibodyloaded beads were prepared as follows. Protein A Dynabeads $^{\text {Tix }}$ (Thermo Fisher Scientific) were washed three times in $1 \mathrm{ml}$ Bead Wash Buffer (BWB). The beads were suspended in BWB with $50 \mu \mathrm{g}$ of rabbit anti-mouse IgG bridging antibody (Jackson ImmunoResearch, West Grove, PA) and rotated end over end at room temperature for $30 \mathrm{~min}$, then washed again with BWB. IgG-loaded beads were then suspended in BWB, incubated with $4 \mu \mathrm{l}$ Anti-pan Ago antibody (clone 2A8; Millipore, Burlington, MA), incubated at RT and washed as described above. Antibody-loaded beads were washed three times with 1xPXL buffer ensuring that beads are fully resuspended with each wash.

CLIP was performed as follows. Cross-linked retinal tissue was suspended in 1xPXL and incubated on ice for $10 \mathrm{~min}$ before lysis by gentle mechanical disruption using sterile pestles. $30 \mu \mathrm{l}$ of RQ1 DNase (Promega, Madison, WI) was added and lysate incubated at $37^{\circ} \mathrm{C}$ for 5 min whilst rotating at 1000 RPM. Lysates were incubated with $10 \mu \mathrm{l}$ of $1 \mathrm{x}$ RNaseA (Affymetrix, Santa Clara, CA) per $1 \mathrm{ml}$ of lysate and incubated at $37^{\circ} \mathrm{C}$ for $5 \mathrm{~min}$. Subsequently, lysates were kept ice-cold to minimize further RNase digestion. Lysates were centrifuged at $16,000 \mathrm{x} \mathrm{g}$ for $40 \mathrm{~min}$ at $4{ }^{\circ} \mathrm{C}$. The supernatant was collected and incubated with the antibody-loaded beads for $2 \mathrm{~h}$ at $4{ }^{\circ} \mathrm{C}$ whilst rotating end over end. The supernatant was removed and beads washed in a series of stringent wash steps: three times in $1 \times P X L ;$ twice in high-salt buffer; twice in high-stringency buffer; 2 times in low-salt buffer; and twice in 1xPNK buffer.

To demonstrate the presence of RNA in AGO2 CLIP complexes, 3' end-labeling followed by gel electrophoresis (SDS-PAGE) was performed. Residual PNK buffer was removed and beads resuspended in desphosphorylation master mix by gentle vortexing. The beads were incubated at $37^{\circ} \mathrm{C}$ for $20 \mathrm{~min}$, whilst shaking at $1000 \mathrm{RPM}$ for $15 \mathrm{~s}$ every $2 \mathrm{~min}$. Beads were washed once with 1xPNK (polynucleotide kinase) buffer, once with 1xPNK supplemented with EGTA and then twice with $1 x P N K$ buffer. 3' linker ligation master mix was added to the beads and incubated. Beads were washed with high-salt buffer, twice with $1 \mathrm{xPNK}$ buffer and then three times with $1 \times$ PNK/EGTA buffer. Residual buffer was removed, beads resuspended in 1xLDS sample-loading buffer (Thermo Fisher Scientific) and incubated at $70{ }^{\circ} \mathrm{C}$ for 15 min, whilst shaking at 1000 RPM. Beads were collected by centrifugation and the supernatant loaded onto a Novex NuPAGE ${ }^{\text {ru }}$ Bis-Tris 8\% gel (Invitrogen, Carlsbad, CA). Proteins were separated at $175 \mathrm{~V}$ for $3-4 \mathrm{~h}$ at $4{ }^{\circ} \mathrm{C}$ in $1 \mathrm{x}$ NuPAGE running buffer (Invitrogen) and then transferred to nitrocellulose membrane (BioRad) for $1 \mathrm{~h}$ at $90 \mathrm{~V}$ in $1 \mathrm{x}$ NuPAGE transfer buffer (Invitrogen) containing $10 \%$ methanol. The membrane was rinsed in PBS, placed in a phosphorimage cassette and exposed to film (GE Healthcare, Chicago, IL) for $24 \mathrm{~h}$. The film was imaged using a Phosphorimager (Typhoon FLA 9500, GE Healthcare). This confirmed the specific immunoprecipitation of AGO2-bound retinal miRNAs and mRNAs, visible as two distinct populations: 1) binary AGO2:miRNA complexes $(110 \mathrm{kDa}) ; 2)$ ternary AGO2: 
miRNA:mRNA complexes ("smear" at $130 \mathrm{kDa}$ ) (Chi et al., 2009, Moore et al., 2014) (Fig. 2B).

To maximise RNA yield, gel extraction of AGO2:RNA complexes was omitted. For RNA recovery following CLIP, bead-bound AGO2 was digested with $4 \mathrm{mg} / \mathrm{ml}$ of proteinase K (Roche Diagnostics). Contamination was controlled for with size enrichment of miRNA and mRNA populations within the AGO2-bound cleaved range [43]. Total RNA was purified with small RNA and mRNA fractions separated as aforementioned.

We exposed C57BL/6 J WT mice to 5 days photooxidative damage and isolated retinas were run through the AGO2 HITS-CLIP protocol (Fig. 2A). Retinal cell suspensions were UV cross-linked, subjected to limited RNase digestions, before AGO2 protein complexes were immunoprecipitation using the Anti-pan Ago antibody (clone 2A8; Millipore, Burlington, MA). This is an AGO2 specific antibody as used in the original AGO2 HITS-CLIP publication [43]. Captured complexes were washed and RNA released by proteinase K digestion.

\section{High-throughput sequencing (HTS) and bioinformatics}

All library preparation and HTS was performed by the Biomolecular Research Facility (JCSMR, ANU). Sequencing libraries were prepared using either the CATS Small RNA-seq Kit (for miRNA samples) or the CATS RNA-seq Kit (for mRNA samples) according to manufacturer's instructions (Diagenode, Denville, NJ). Libraries were sequenced on an Illumina HiSeq 2500, acquiring single-end reads of $51 \mathrm{bp}$ for the global miRNA and HITS-CLIP experiments or $76 \mathrm{bp}$ for the global mRNA experiment. Raw reads were processed with cutadapt to trim adaptors, artefact bases and barcodes. FASTQC sequence quality analysis were performed before and after cleaning. The average clean read length was $20 \mathrm{nt}$ and $45 \mathrm{nt}$ for miRNA and mRNA libraries, respectively.

Global high-throughput sequencing (HTS) of retinal miRNAs and mRNAs was performed to analyze overall changes in the retina between dim and 5 days $\mathrm{PD}$ mouse retinas. 47-71 million cleaned reads were obtained, reads aligned to the mm10 mouse genome and annotated according to RefSeq (Table S1). 3-9 million and reads were obtained and aligned to the mature mouse miRNA sequences downloaded from miRbase (Table S2).

Clean mRNA reads were aligned to the mm10 genome sequence with Burrows-Wheeler Aligner, bwa-mem [44] and samtools [45] was used for sorting and statistical analysis. Mapping statistics are shown in Table S1. Mapped reads were summarized using FeatureCounts [46] and annotated based on the genomic coordinates provided by Refseq. Trimmed Mean of M-values (TMM) [47-49] was used for normalization. Differential expression was analysed using the voom-limma package [47] with a linear model fit and Bayes' adjustment of $p$ values to account for type I errors and multiple comparisons. Significance was determined as adjusted $P<0.05$.

Mouse mature miRNA sequences were downloaded from miRbase [44, 50] and clean reads were separately aligned first to mouse mature miRNA and pri-miRNA sequences then to mm10 mouse reference genome using bwa-aln [44]. awk, samtools [45] and FeatureCounts [46] were used for count sorting and summary. Mapping statistics are shown in Table S1. Alignments were summarized using a Unix shell script (awk and grep) for reads with mapping quality above 20 . The miRNAs were ranked based on their mean expression level. TMM method was [47-49] used for normalization and the voom-limma package with sample quality weights was used for detecting differentially expressed genes. For a robust differential expression analysis, only miRNAs with $C P M>10$ in at least four out of the eight samples were used. Hierarchical clustering was performed using the heatmap. 2 function on $\mathrm{R}$ against the top 80 differentially expressed miRNA in the global database.

\section{Enrichment analysis}

For peak calling, the mm10 genome alignment files were converted to the bed format and peaks called using Homer (http://homer.ucsd.edu/homer/), for PD and dim groups separately. Peak findings were analyzed using Factor styles which aims to identify the precise location of nucleic acid to protein contact. We used a fixed width peak size of $75 \mathrm{bp}$ which was automatically estimated from the Tag Autocorrelation. The peaks were annotated using Homer (annotatePeaks.pl), extracted and separated into different regions (exon, intron, transcription termination site (TTS), ncRNA, miRNA, 5' UTR, 3' UTR). 3' UTR peaks were searched for enriched sequence motifs using Homer (findMotifs.pl). The significantly expressed miRNAs and their targets were matched based on the motifs, their expression levels, and cross-referenced with our results from global miRNA and mRNA experiments.

For pathway enrichment, mRNA targets of the top 20 miRNA were identified by TargetScan [8] and miRNet [51]. These targets were batch-filtered and crossreferenced with the AGO HITS-CLIP mRNA data to yield functional mRNA targets. Enriched biological gene ontology processes were determined using Gorilla [52]. $P$-values were adjusted for multiple comparisons using the Benjamini-Hochberg method with terms with $>3$ genes and $P<0.05$ were deemed significantly. REVIGO was used for visualization of term clustering. Enrichment analysis was conducted for both up-regulated and downregulated mRNA datasets. For in-depth pathway analysis, GSEA was performed with camera [53] against the 
gene sets listed in the Hallmark and $\mathrm{C} 2$ pathways from the Molecular Database (MsigDB v5). $P<0.05$ was deemed significantly enriched.

\section{Single cell RNA sequencing (scRNA-seq)}

mRNA expression for AGO2 and differentially expressed miR-124-3p targets (AGO2 HITS-CLIP) across retinal cell types was retrieved from a publicly available scRNA-seq database deposited by Macosko et al. [54] (GSE63473, Gene Expression Omnibus). The cells in this database were obtained from whole retina cell suspensions of wild-type, dim-reared C57BL/6 mice. All data processing steps were performed with BioTuring Browser, version 2.7.48 for Mac OS (BioTuring Inc., San Diego, California, USA). Expression matrices were imported into BioTuring Browser in MTX format and quality-filtered for cells with min. 200 genes/cell and $<5 \%$ mitochondrial gene ratio, finally retaining 13,189 cells. Dimensionality reduction was performed by $\mathrm{t}$-distributed stochastic neighbor embedding ( $t$-SNE) on the first 30 principal components with perplexity set at 30 . Next, graph-based clustering was performed (Louvain algorithm) and cell-types were annotated according to the cell markers supplied in the original publication. This dataset was queried for the expression of AGO2 and miR-124-3p targets and the results of this query were graphically displayed using ggplot2 package [55] in R [56].

\section{Western blotting}

Retinas from dim and PD mice were lysed in CellLytic ${ }^{\mathrm{Tm}}$ Cell Lysis Buffer (Sigma-Aldrich, MO, USA) supplemented with a protease inhibitor cocktail (Sigma-Aldrich). A total of $20 \mu \mathrm{g}$ of protein was reduced and denatured then subjected to electrophoresis on a Novex ${ }^{\mathrm{TM}}$ 4-20\% Tris-Glycine Mini Gel (Thermo Fisher Scientific). After separation, the protein was transferred to a nitrocellulose membrane (Bio-Rad, CA, USA), blocked in 3\% BSA/PBS for $1 \mathrm{~h}$, then incubated in primary antiArgonaute-2 antibody (1:1000, ab32381, Abcam, Cambridge, UK) overnight at $4{ }^{\circ} \mathrm{C}$. The following day, the membrane was incubated for $2 \mathrm{~h}$ in a HRP-conjugated Goat Anti-Rabbit IgG $(\mathrm{H}+\mathrm{L})$ secondary antibody (BioRad) and developed with the ClarityTM Western ECL Substrate (Bio-Rad). After development, the membranes were imaged using the ChemiDoc ${ }^{\mathrm{Tm}}$ MP Imaging System with Image Lab ${ }^{\text {th }}$ software (Bio-Rad). GAPDH (G9545, Sigma-Aldrich) was used a protein loading control.

\section{Immunohistochemistry}

Immunohistochemistry was performed as previously published [14]. Briefly, mouse eyeballs were enucleated, fixed in $4 \%$ paraformaldehyde, dehydrated and embedded in Tissue-Tek ${ }^{\bullet}$ Optimal Cutting Temperature
Compound (Sakura Finetek, California, USA). $12 \mu \mathrm{m}$ cryo-sections were rehydrated, blocked for $1 \mathrm{~h}$ in $10 \%$ Normal Goat Serum then probed with primary antibody overnight at $4{ }^{\circ} \mathrm{C}$. Immunofluorescence signal was developed with Alexa Fluor IgG secondary antibodies for $2 \mathrm{~h}$ at RT, followed by nuclei counterstaining with Hoechst 33342 (Sigma-Aldrich). Antibodies: anti-Argonaute-2, 1:500, ab32381, Abcam; antiglutamine synthase, 1:500, Abcam; anti-rabbit IgG Alexa Fluor $488 \mathrm{~nm}$ and $647 \mathrm{~nm}$, ThermoFisher.

\section{In situ hybridization}

Complementary DNA was synthesised from retinal RNA as described previously [14]. A $445 \mathrm{bp}$ region of the mouse AGO2 mRNA (NM_153178.4) was amplified using the forward primer GAGACAGTCCACCTCTTG TGG and reverse primer GCCCAGAAGCAAACAACA CC. The reverse primer was extended with a T7 RNA Polymerase tag ATATATTAATACGACTCACT ATAGG at the $5^{\prime}$ end. A total of 35 PCR cycles (melting $\left(95^{\circ} \mathrm{C}, 15 \mathrm{~s}\right)$, annealing $\left(60^{\circ} \mathrm{C}, 15 \mathrm{~s}\right)$, extension $\left(72{ }^{\circ} \mathrm{C}\right.$, 10s)) were carried out and the presence of the correct amplicon was verified using electrophoresis on a $1 \%$ agarose gel. After amplification, the PCR product was mixed with $1 / 4$ of ammonium acetate and 10 volumes of ice-cold absolute ethanol. The PCR product was centrifuged $\left(13,000 \mathrm{~g}, 15 \mathrm{mins}, 4^{\circ} \mathrm{C}\right)$, then the pallet was washed with $70 \%$ ice-cold ethanol then re-precipitated $\left(13,000 \mathrm{~g}, 2 \mathrm{mins}, 4^{\circ} \mathrm{C}\right)$. The ethanol was removed and the PCR product was reconstituted in Ultrapure water (Gibco, Thermo Fisher Scientific). The purity and concentration of the reconstituted PCR product was assessed on a ND-1000 spectrophotometer (Nanodrop Technologies, DE, USA). A riboprobe was transcribed from the PCR template using a T7 RNA polymerase (Promega, Madison, WI), incorporated into digoxigenin (DIG) SP6/T7 RNA polymerase (Roche, Basel, Switzerland), then hybridised to cryso-sections as previously published [57]. Optimum hybridisation for AGO2 probe was achieved at $59^{\circ} \mathrm{C}$ overnight. Unbound probe was washed with saline sodium citrate $\left(\mathrm{pH} \mathrm{7.4)}\right.$ at $60^{\circ} \mathrm{C}$ and developed using nitro blue tetrazolium and 5bromo-4-chloro-3-indolyl phosphate (NBT/BCIP) (Sigma Aldrich) for $60 \mathrm{~min}$. The reaction was stopped by washing in ultrapure water and the slides were mounted with Aqua-Poly/Mount.

\section{Image acquisition and processing}

Images were captured on a Nikon $\mathrm{Al}^{+}$confocal microscope operated via NIS-Elements AR software (Nikon, Tokyo, Japan) acquiring sequential $0.3 \mu \mathrm{m}$ z-stacks followed by maximum intensity projection processing. AGO2 in situ hybridisation labelling was captured either using a colour DS-Ri1-U3 colour camera fitted on the 
Nikon A1+ system or differential interference contrast (DIC) imaging. For DIC images, labelled areas were selected using 16-bit image thresholding in Image v2.1 (NIH, Bethesda, MD, USA) [58] then pseudo coloured. For colocalization analysis, raw confocal files were imported into ImageJ v2.1 and converted to 16-bit. Consistent pixel intensity thresholds were applied to both channels using JACoP plugin [59] such that only area with clear labelling were included in the colocalization analysis then Pearson's correlation coefficient was calculated. Colocalised pixel were pseudo-coloured using ColocalisationFinder plugin.

\section{Data availability and user-friendly exploration}

Datasets supporting the conclusions of this article are available on the Sequence Read Archive (PRJNA606092) as part of the National Center for Biotechnology Information (NCBI). Processed RNA-seq data can be interactively explored at: https://genedatasets.shinyapps.io/ ARMMI/

\section{Results \\ Global miRNA and mRNA transcriptomes reveal key miRNA and inflammatory pathways involved in retinal degeneration induced by PD}

Retinal RNA was extracted and sequenced from dim and $\mathrm{PD}$ retinas to compare differences in gene expression following retinal degeneration (Fig. 1A). A twodimensional principal component analysis (PCA) was employed to visualize differences in RNA profiles between the groups, which showed clear inter-group clustering with clear segregation between $\mathrm{PD}$ and dim retinas (Fig. 1B). Despite inherent animal variability displayed in the "dim 1" retina, the animals all responded similarly to PD with close intra-group clustering. Differential expression analysis identified 3018 mRNA transcripts to be significantly changed between dim and PD retinas based on an adjusted $P$-value of less than 0.05 (Fig. S1A). Hierarchical clustering of the top 80 differentially expressed mRNA revealed strong correlations intra-group (Fig. 1C). Gene set enrichment analysis (GSEA) against the C2 collection from the Molecular Signatures Database (MSigDB) was used to decipher enriched pathways of these differentially expressed mRNAs. Enrichment analysis of the differentially expressed mRNAs revealed 203 significantly enriched terms/pathways (Fig. 1D, Table S5, $P<0.05$ ). Among the most highly enriched terms were pathways involved primarily in the inflammatory response and innate immune system such as the monocyte pathway, cytokine and interleukin signaling, interferon signaling and many facets of the complement pathway including the lectin and classical pathways (Fig. 1D, Table S5) were all upregulated consistent with previous work demonstrating the key role of the innate immune response in the progression of retinal degenerations [17, 18]. Further, cone and rhodopsin pathways were downregulated (Fig. 1D, Table S5), indicating photoreceptor dysregulation consistent with the expected effects of the PD model [42].

Concurrent with the mRNA analysis, small RNA were extracted and sequenced to conduct analyze specifically analyze differences in miRNA profiles between dim and PD retinas. miRNA analysis identified 287 significantly differentially expressed miRNAs between dim and PD retinas (Fig. S1B, $P<0.05$ ). PCA showed clear clustering between the two groups suggesting a unique miRNA profile and differences between dim and PD retinas (Fig. 2B). The top 80 differentially expressed miRNAs showed highly similar expression within the same group, but considerably different expression between dim and PD groups (Fig. 1C). Among the top 10 most significantly different miRNAs were those known to be involved in maintaining retinal neuronal homeostasis [60], including miR-9-5p (down-regulated), miR-211-5p (down-regulated) and miR-191-5p (up-regulated) (Fig. 1C, S1B). Taking the top 20 most highly-expressed miRNAs, there was again a distinct difference between dim and PD groups with 14 out of the 20 miRNAs statistically significant $(P<0.05$, Fig. 1D). Interestingly, the top 20 most abundant miRNAs represented $85 \%$ of the total retinal miRnome in both the dim and PD (Fig. 1E-F) retinas, with let-7 family members, photoreceptor-enriched miR183-5p and miR-182-5p as well as neuron-enriched miR-124-3p the most highly expressed miRNAs. Collectively, these results demonstrate that only a small set of miRNAs represents the overwhelming majority of the total retinal miRnome and that they are largely involved in pathways regulating the innate immune system.

\section{AGO2 HITS-CLIP reveals active retinal miRnome and mRNA targetome}

Whilst the global transcriptome analysis provides a snapshot of the molecular and physiological processes that occur in response to photoreceptor retinal degeneration, AGO2 HITS-CLIP was performed to decipher the functional miRnome and its respective targets (Fig. 3A-C).

mRNA sequencing yielded $\sim 30$ million raw reads per sample, which were cleaned and aligned to the mm10 mouse genome (Fig. 3D, Table S3). Data consistency and reproducibility was visually evident amongst the groups looking at the positional read coverage of key visual transduction genes (Fig. 3E). Small RNA sequencing yielded $\sim 5$ million raw reads per sample, which were trimmed and aligned to the mature mouse miRNA sequences obtained from miRBase (Fig. 3F, Table S4). Differential analysis did not reveal any change in accumulation of AGO2-bound miRNAs between dim 


\section{A Experimental Paradigm}

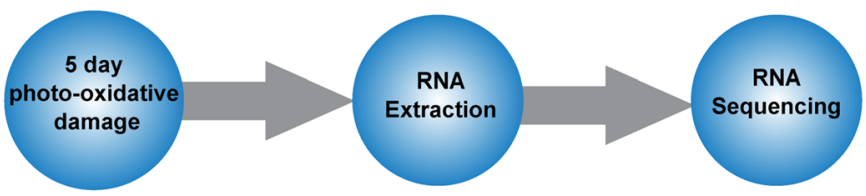

B PCA

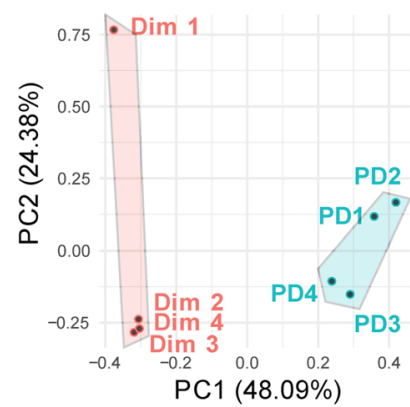

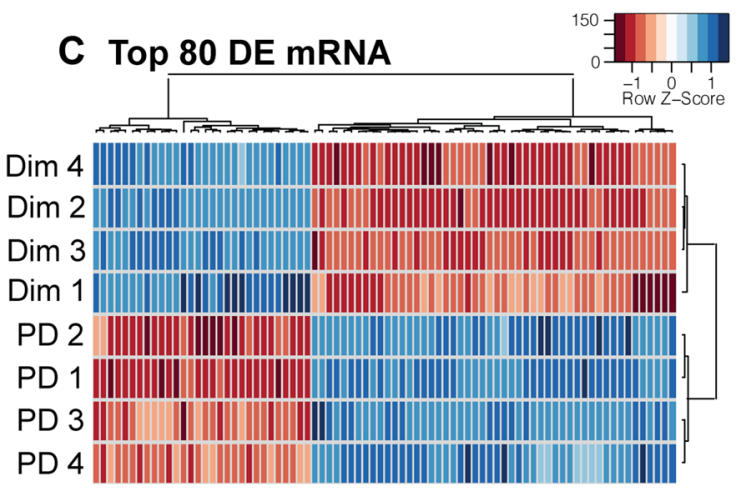

D

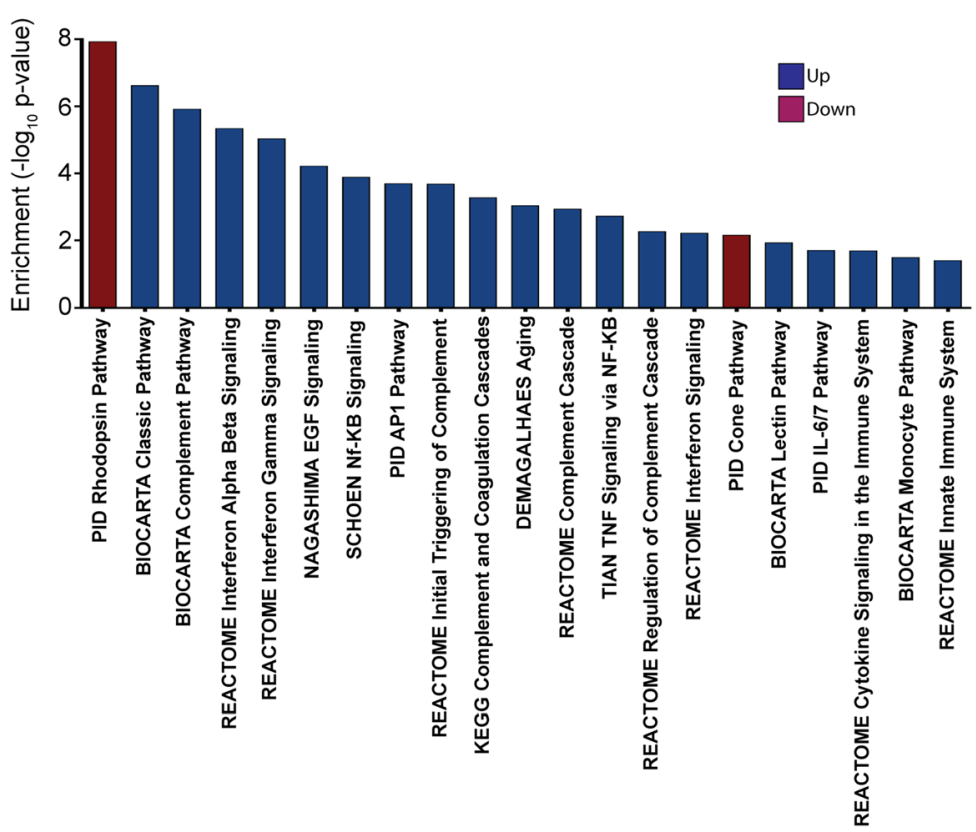

Fig. 1 Global retinal mRNA expression profile determined by high-throughput sequencing (HTS). (A) Retinas from mice subjected to 5 days photo-oxidative damage (PD; $n=4)$, or dim-reared controls (dim; $n=4)$, were collected and RNA extracted. Sequencing libraries were prepared and subjected to HTS Illumina sequencing. Obtained reads were cleaned and trimmed and aligned to the mm10 mouse genome. (B) Principal Component Analysis (PCA) demonstrated tight clustering of the dim and PD groups with the exception of dim sample 1. (C) Hierarchical clustering was performed with for the top 80 differentially expressed mRNA and illustrated with a heat map. Sample specific expression level of each mRNA is indicated by the z-score color scale. (D) Gene set enrichment analysis (GSEA) for all differentially expressed mRNAs was performed against the C2 database with down-regulated pathways indicated in red and up-regulated pathways in blue $(P<0.05)$

and PD samples. This demonstrates the importance of functional validation in miRNA analysis as the nonAGO2 HITS-CLIP results differed showing a change in expression. To understand the dynamics within both homeostatic and degenerative conditions, we continued our analysis into dim and PD datasets separately.
From the identified miRNA in the AGO2-bound miRNA dataset, the top 20 miRNA were run through TargetScan to get an output of their predicted targets (Fig. 4A). The predicted targets were then filtered through our AGO2-bound mRNA dataset to identify functional targets in the retina (Fig. 4A). 556 AGO2- 


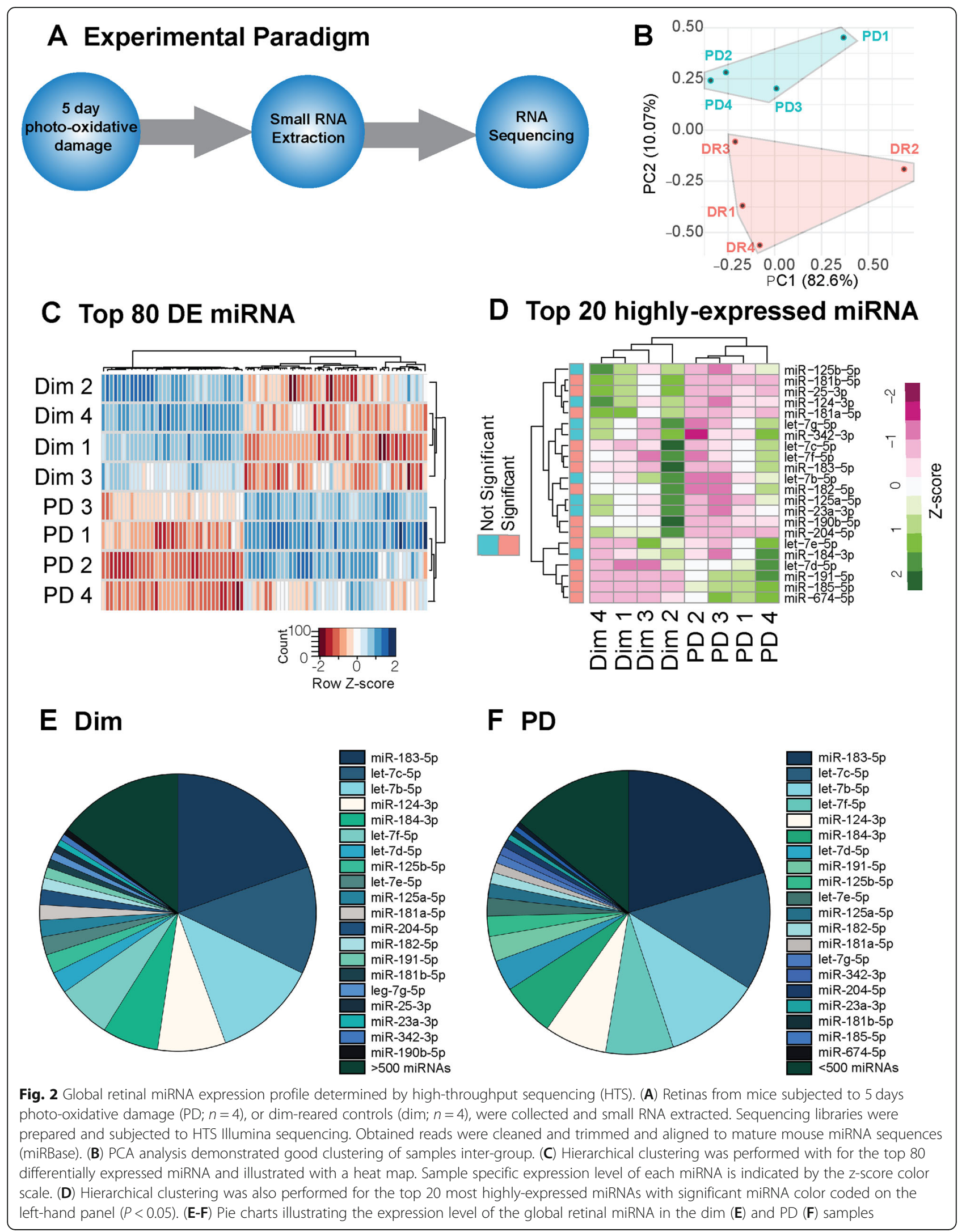




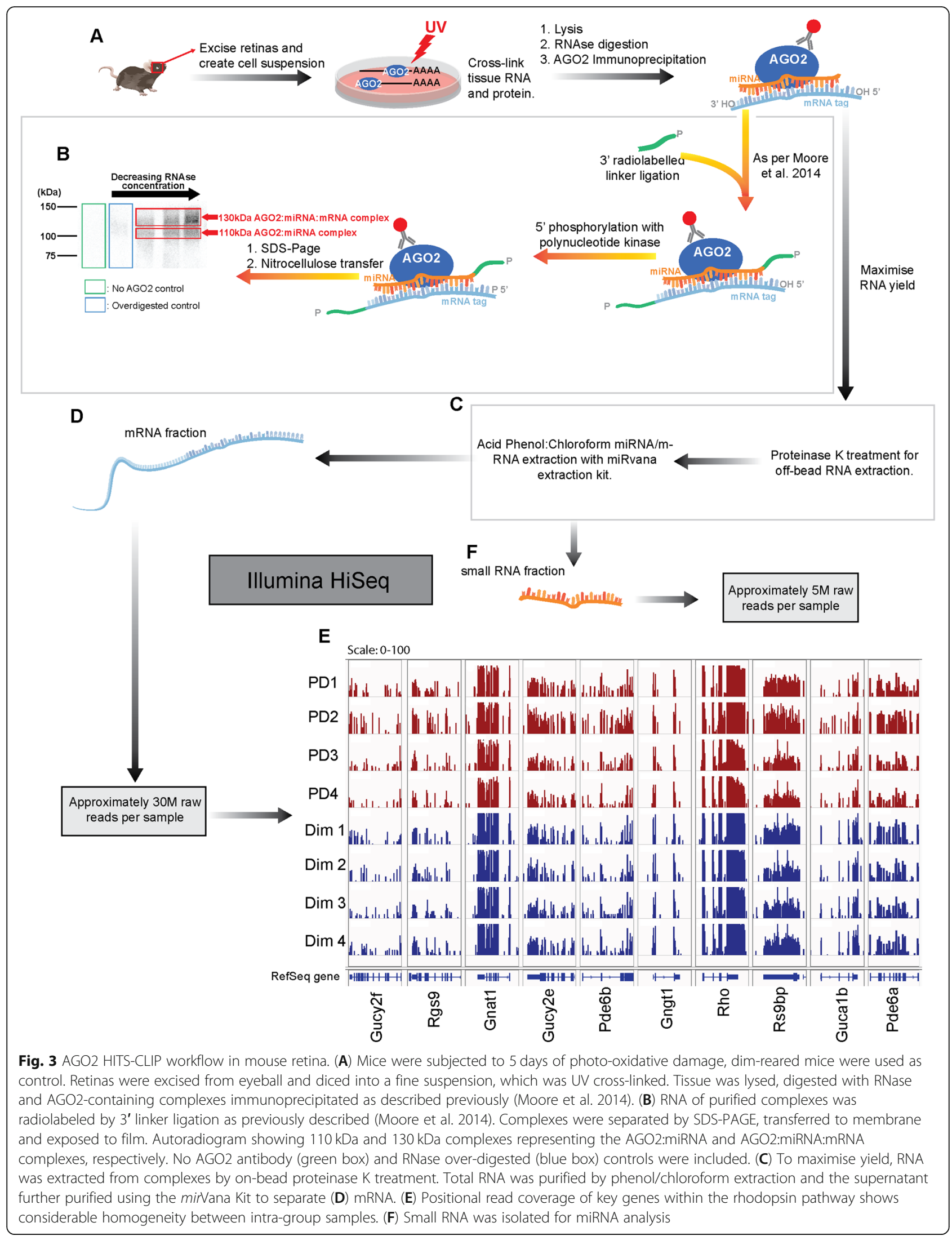


bound miRNAs in dim retinas were identified. Interestingly, miR-124-3p was the most prominent, representing $75 \%$ of the AGO2-bound miRnome (Fig. 4B). Photoreceptor specific miR-183-5p (part of a cluster miR182/ 96/183) [1, 61-64] was the second most abundant miRNA followed by miR-124-5p. The remaining top 10 miRNAs included miR-125b-5p, miR-125a-5p, miR181a-5p, miR-191-5p and three members of the miR-29 family: miR-29a-3p; miR-29b-3p; and miR-29c-3p. The other two members of the photoreceptor cluster, miR182-5p and miR-96-5p, were among the top 20 AGO2bound miRNAs in dim retinas. miR-301a-3p, miR-130a3p, miR-204-5p, miR-99b-5p, miR-29b-1-5p, miR-342$3 p$ and two members of the let-7 family (let-7d-3p and let-7f-5p) completed the top 20.554 AGO2-bound miRNAs were identified in PD retinas (Fig. 4B). Similar to the dim retinas, miR-124-3p was the most abundant constituting $81 \%$ of the AGO2-bound miRnome. miR-

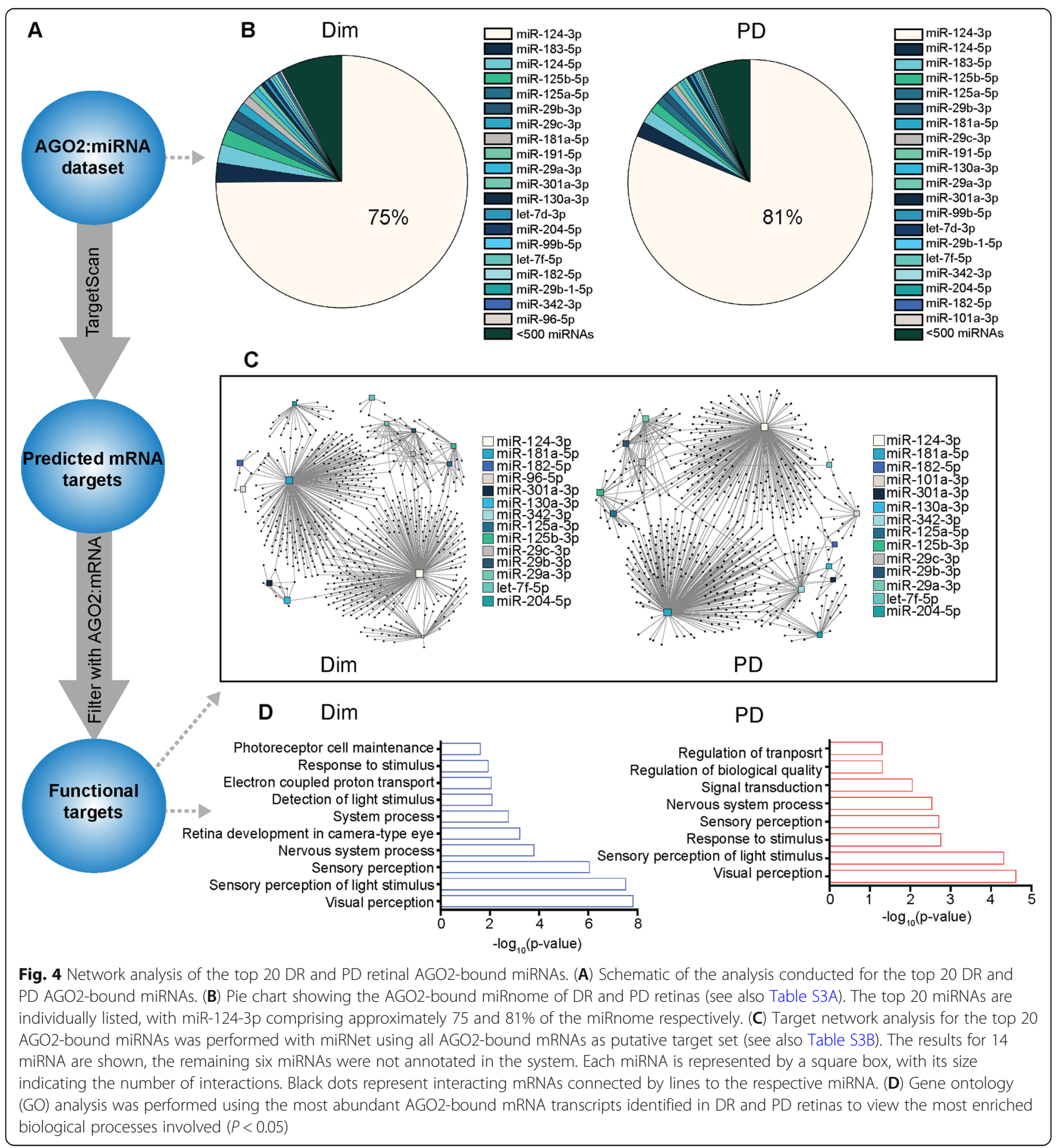


124-5p and miR-183-5p were second and third most common miRNA bound to AGO2, respectively. The top 20 AGO2-bound miRNA identified in PD retinas were almost identical to those found in dim retinas, with each having slightly different overall abundances (Fig. 4B).

To determine the size and breadth of the predicted miRNA/mRNA target networks, miRNet analysis was performed with the top 20 AGO2-bound miRNAs using all identified AGO2-bound mRNAs as the putative target set. This revealed mRNA targets for 14 miRNAs (Fig. 4C) with the remaining six (miR-183-5p, miR-1245p, miR-191-5p, let-7d-5p, miR-99b-5p, miR-29b-1-5p) not well annotated in miRNet. Among them miR-124-3p and miR-181-5p returned the majority of mRNA target interactions, with 223 and 233 interactions each, respectively (Fig. 4C). The PD dataset also yielded networks for 14 of the top 20 AGO2-bound miRNA (Fig. 4C). As with the dim retinas, miR-124-3p and miR-181-5p showed the highest number of interactions (Fig. 4C). The most enriched biological processes for the AGO2-bound mRNA ranked based on abundance were somewhat similar in both dim and PD datasets with processes involved in visual processing, such as visual perception and sensory perception of light stimulus, being the most enriched in both (Fig. 4D).

Here, breadth of the miR-124-3p networks and size of their population amongst the functional miRnome of both dim and PD retinas was demonstrated. Further, the functional AGO2-bound miRnome is overwhelmingly involved in standard visual processes of the retina, indicating a homeostatic role for vision and retinal maintenance that remains important under stress.

\section{Retinal AGO2-bound miRNAs shift their mRNA targetome following PD}

Although AGO2-bound mRNA enriched GO terms between dim and PD samples were similar, differences in mRNAs contributing to those GO terms was investigated. Differential expression analysis was performed and identified 96 mRNAs that are differentially bound to AGO2 following PD with 44 up-regulated and 52 downregulated $(P<0.05)$. Functional enrichment analysis for gene ontology biological processes on the AGO2-bound mRNA dataset ranked by $p$-value was then conducted. The datasets were split into two groups: 1$)$ up-regulated genes in PD compared to dim (Table S6); 2) downregulated genes in PD compared to dim (Table S7). Enriched biological processes were clustered using REVIGO to better visualize the gene ontology output. For up-regulated genes there were obvious clusters for the immune response and regulation of signaling and response processes (Fig. 5A). The majority of enriched terms, as measured by $\log _{10} \mathrm{p}$-value, were immune and stress response related. For down-regulated genes there was clustering observed for visual perception, metabolism and light response processes (Fig. 5B). A breakdown of the enriched $\mathrm{GO}$ processes corroborates the clusters with the majority of the GO terms associated with the visual pathway. Full GO including molecular function and cellular component can be found in Tables S8 and S9 in the supplementary data.

To further explore the specific pathways up- or downregulated in the AGO2-bound mRNA dataset, gene set enrichment analysis (GSEA) against the $\mathrm{C} 2$ collection from the MSigDB was performed $[65,66]$. Selected pathways were then sorted into the following categories: cell death and motility; stress response; visual transduction; and immune response (Fig. 5C). Enriched pathways under the cell death and motility, stress response and immune response categories were largely up-regulated in $\mathrm{PD}$ retinas. Included in these categories are the complement pathway, NF-KB signaling, IFN alpha and beta signaling and apoptotic pathways, all known to play roles in retinal degeneration [18]. Notably, the four pathways categorized under visual transduction all were downregulated. These results indicate that, whilst maintenance of the visual system remains a priority for the retinal miRnome, there is a nuanced change in mRNA targeting by active AGO2-bound miRNAs following photo-oxidative damage. The activity of AGO2-bound miRNAs appears to shift its focus from visual transduction, to the retinal response under duress particularly targeting genes involved in inflammatory pathways and the immune response.

\section{miR-124-3p undergoes shift in seed binding region following PD}

Given the changes in AGO2-bound mRNAs following $\mathrm{PD}$, the binding interactions of the AGO2-bound miRNAs with their targetome was analyzed next. We performed peak calling of the reads aligning to the 3531 unique AGO2-bound mRNA transcripts identified in dim and PD retinas. Identified peaks were annotated according to transcript region (according to RefSeq) and subjected to motif enrichment analysis (HOMER). The most enriched sequence motifs within the 3' UTRs of the AGO2-bound mRNAs in dim retinas matched the exact sequence of the miR-124-3p seed region (Fig. 6A). Where as in PD retinas we found that the most enriched sequenced motif matched the eight nucleotide reverse complementary seed region of miR-124-3p indicating regulation of miR-124-3p specific targets. All four canonical seed regions were represented: 6-mer (reverse complement of miRNA positions 2-7); 7A1 (reverse complement of miRNA positions 2-7 with an adenine base); $7 \mathrm{~m} 8$ (reverse complement of miRNA positions $2-$ 8); and 8-mer (reverse complement of miRNA positions 2-8 with an adenine base) (Fig. 6B). To determine the 


\section{A Biological processes enriched by up-regulated genes}

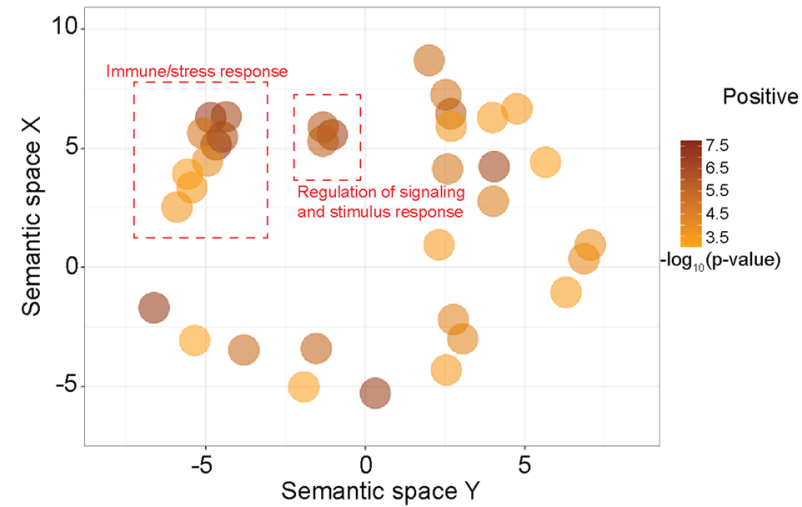

Regulation of cytokine production - 24 Defense response- 26

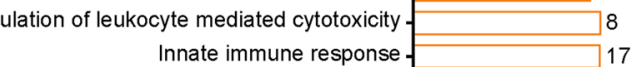

Cell surface receptor signaling pathway- 63

Regulation of immune system process - 21

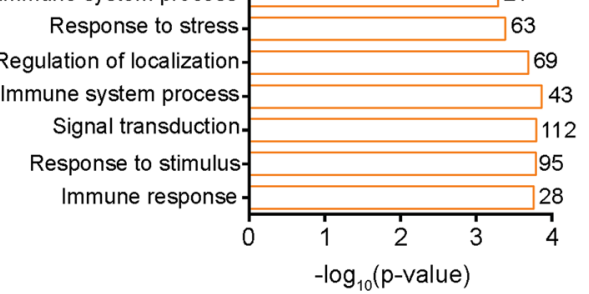

B Biological processes enriched by down-regulated genes

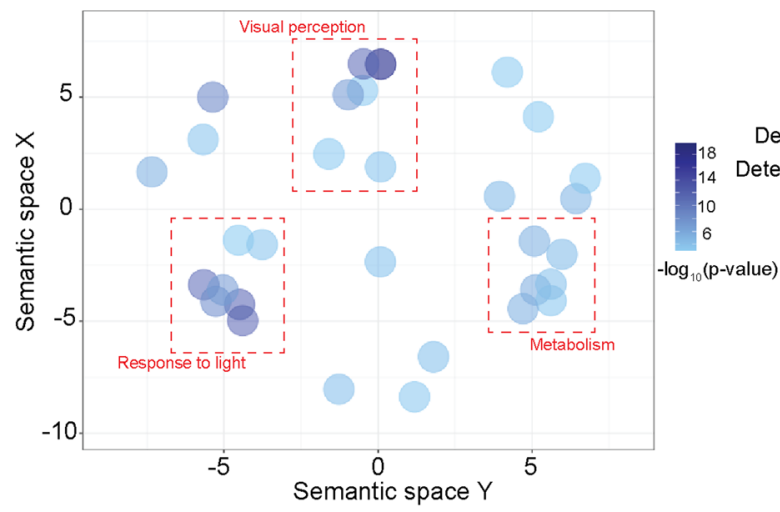

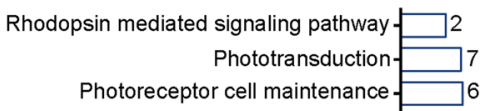

Detection of light stimulus involved in visual perception- $\square$

Detection of light stimulus involved in sensory perception -5

Retina development in camera-type eye- 7

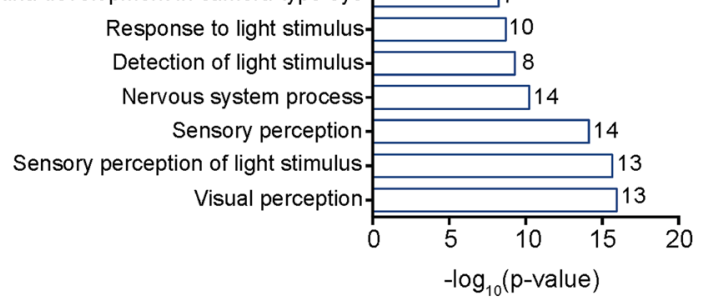

C
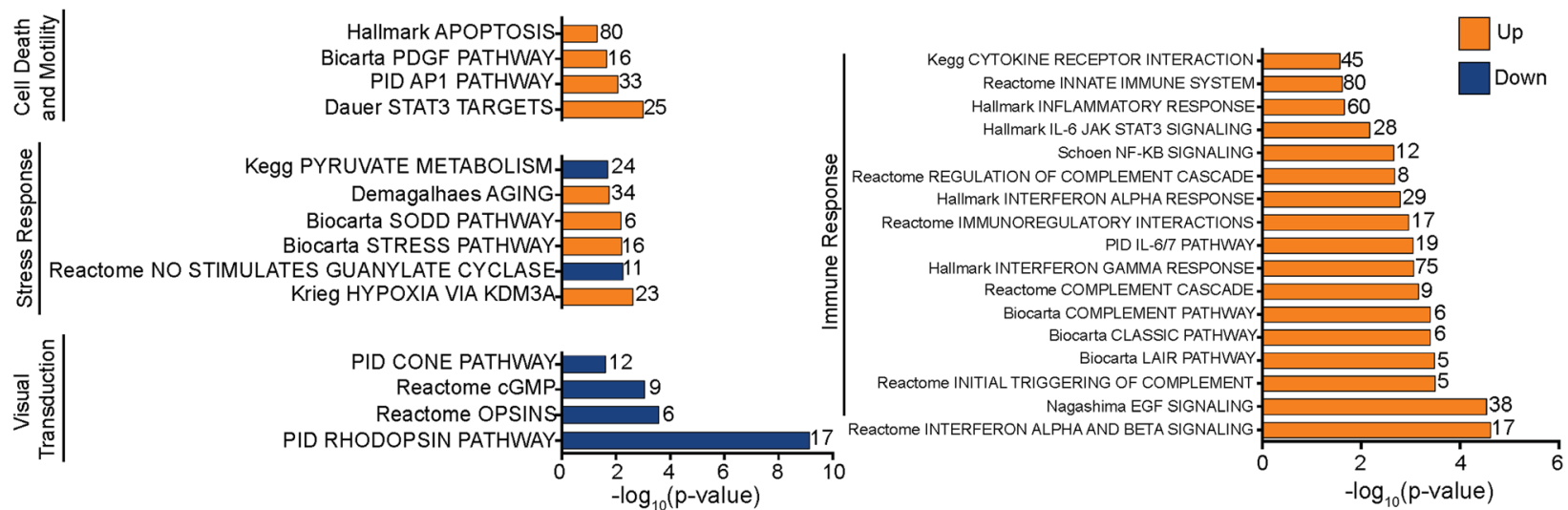

Fig. 5 Pathway enrichment of differentially bound AGO2 mRNA in PD retinas. (A) Up-regulated AGO2-bound mRNA were analysed for GO biological process enrichment with significant terms clustered with REVIGO for visual analysis. (B) The same process was performed for downregulated genes in PD retinas. (C) Gene set enrichment analysis (GSEA) was performed using a ranked list of the differentially AGO2-bound mRNAs against the C2 database for enriched pathways. Selected pathways were separated into four groups: cell death and motility; stress response visual transduction; and immune response $(P<0.05)$. Numbers accompanying the bars represent the number of genes associated with the respective pathway

extent to which miR-124-3p might regulate its targets within the retina, AGO2-bound mRNAs that are predicted binding partners of miR-124-3p as indicated by TargetScan were tabulated (Table S10). Up-regulated targets, as represented by a positive log fold change, in
PD retinas compared to dim is indicative of increased binding. A number of these transcripts have wellestablished links to retinal degeneration, including chemokine C-C motif ligand 2 (Ccl2) [67] and rhoassociated protein kinase 2 (Rock2) [68]. The cellular 


\section{A Dim enriched motif}

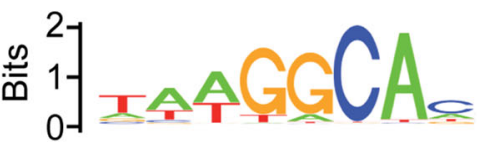

miR-124-3p ( $T$ for U substitute)

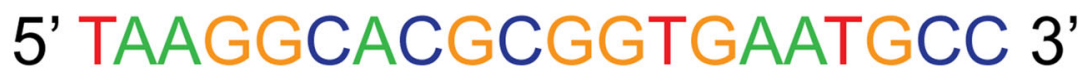

Canonical seed region

\section{B PD enriched motif}

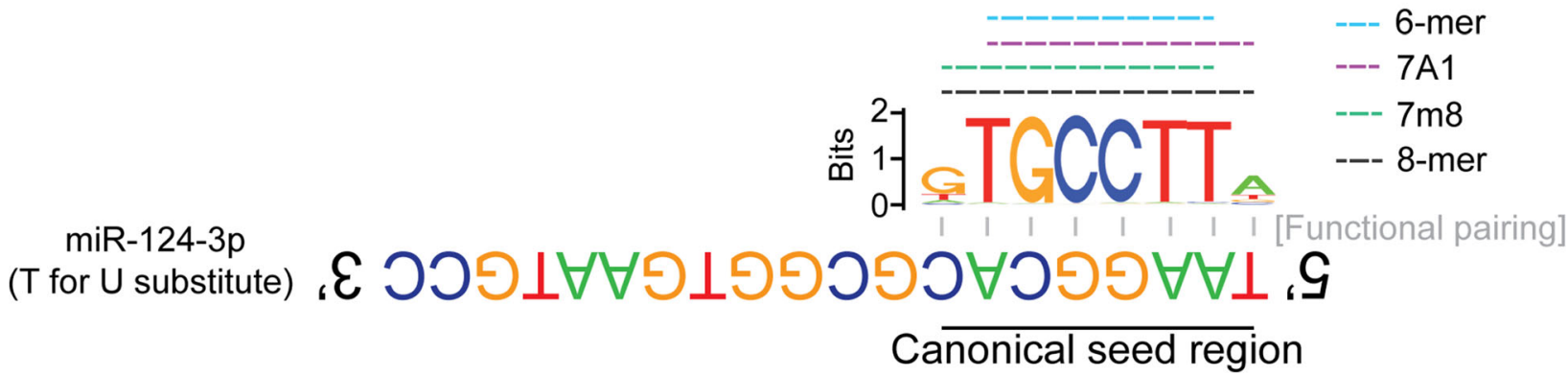

Fig. 6 Enriched sequence motifs of AGO2-bound mRNA. Peak calling (HOMER) of reads mapped to AGO2-bound mRNAs was performed for DR and PR samples. Peaks were annotated according to transcript region and subjected to motif enrichment analysis (HOMER). The most highly enriched motif for each sample is shown here. For easy orientation, the CDNA sequence of miR-124-3p is displayed at the top, with positions 1-6 indicated by the dashed box and positions 2-8 indicated by the solid box. (A) The top most enriched binding motifs of AGO2-bound mRNAs in dim retinas was the exact sequence of the miR-124-3p seed region. (B) The most enriched binding motifs of AGO2-bound mRNAs in PD retinas are the reverse complement of positions 2-8 (or 1-8 for the 8-mer motifs) of the miR-124-3p binding regions encompassing all canonical seed regions as indicated with the colored lines

location and baseline expression of the top 10 most differentially expressed miR-124-3p targets are highlighted in Fig. 6B using publicly available single-cell RNA data as described in the next section.

Taken together, this data indicates that following PD, a change in miR-124-3p miRNA target activity occurs, which coincides with an increased AGO2 movement within the retina. These changes may reflect a key aspect of miRNA function under duress that results in a translocation within retinal maintenance cells to regulate differentially expressed disease-specific pathways in the retina.

\section{Expression of Ago2 changes upon retinal damage}

AGO2 HITS-CLIP was performed using whole retinal lysates, however the expression of AGO2 across retinal cell types remained to investigated. The re-analysis of scRNA-seq data [54] indicated that AGO2 mRNA is present in both retinal neurons (photoreceptors, bipolar cells, amacrine cells, horizontal cells and retinal ganglion cells) and retinal glia (Müller glia and astrocytes; Fig. 7A and B) under normal dim conditions. Within each cluster AGO2 expression was variable ranging from 0.74 to $2.35 \log$ normalized UMI counts (Fig. 7B) with average expression of similar magnitudes for photoreceptors, bipolar cells, amacrine cells and Müller glia and comparatively reduced expression for retinal ganglion cells, horizontal cells and astrocytes (Fig. 7C). To further study the expression of AGO2 within the mouse retina, we probed both AGO2 mRNA and protein expression using immunohistochemistry, western blot and in situ hybridization at a range of retinal eccentricities in dim and $\mathrm{PD}$ retinas (Fig. 8A).

In line with the scRNA-seq, in situ hybridization showed AGO2 mRNA expression in heathy retinas within the cell bodies of RGCs, the inner and outer regions of the INL with an accentuation in expression in the peripheral retina ( $\mathrm{cf}$ central retina) (Fig. 8B i). PD resulted in increased $A G O 2$ mRNA expression, localized within the INL and GCL in the inferior retina and at the lesion site (Fig. $8 \mathrm{~B}$ ii). The superior retina proximal to the lesion site also showed increased AGO2 expression across the INL and GCL, however AGO2 was also detected within the ONL here and 


\section{Single cell RNA-seq}

\section{A Retinal cell types}

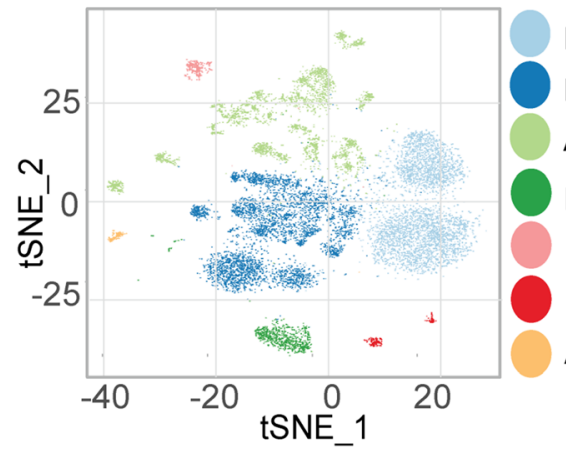

Photoreceptors (4097)

Bipolar cells (4367)

Amacrine cells (3226)

Muller glia (835)

Retinal Ganglion Cells (274)

Horizontal cells (242)

Astrocytes (148)
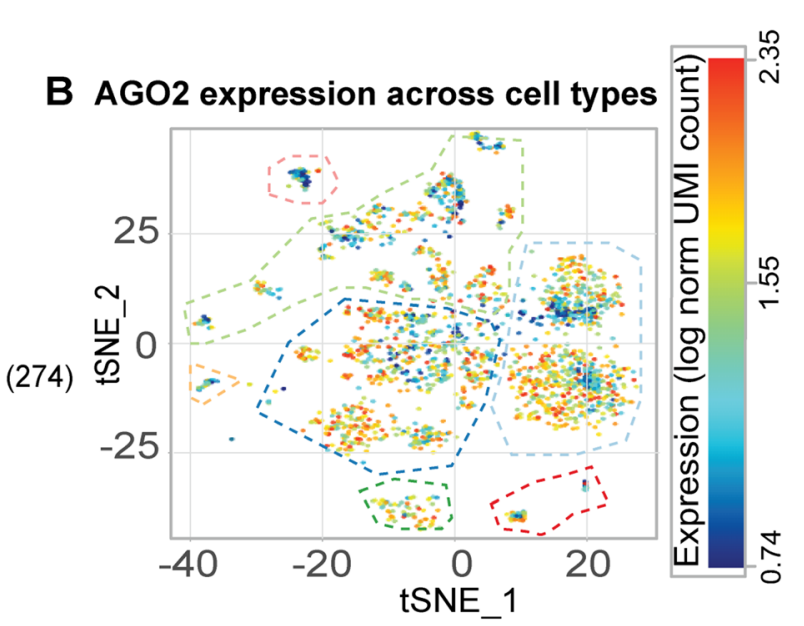

\section{Mean AGO2 expression}

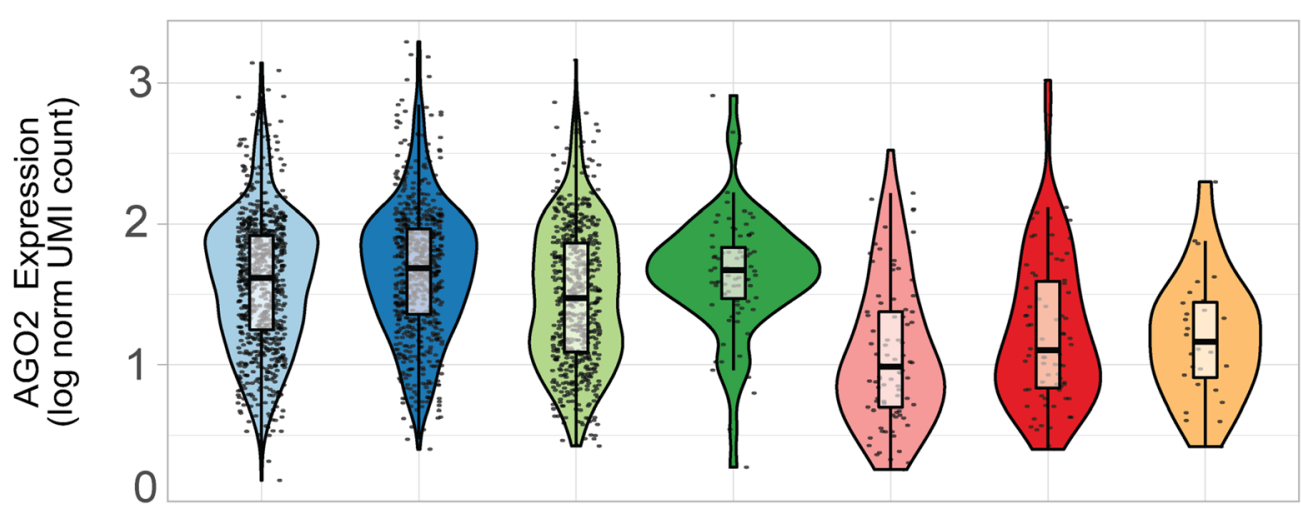

Fig. 7 Cellular location and expression of AGO2 mRNA and mir-124-3p targets derived from publicly available scRNA-seq data. (A) t-SNE plot showing 19 retinal cell populations ascribed to a major class of retinal cell types indicated by colour-coding. Value between parentheses show the number of cells within each cluster. Colour coding applies to all subsequent plots in this Fig. (B) AGO2 expression levels across all cells with AGO2 expression $>0$. Areas enclosed by dashed lines indicate the predominant cell population occupying that region of the t-SNE plot identified according to the colour-coding depicted in A. (C) AGO2 expression for each cell class depicted in ii represented as box plots showing the median values, Q1 (25th) and Q3 (75th) quartiles. Whiskers extend 1.5 times above and below and interquartile range. Each point corresponds to the expression of a single cell within that cluster

the outer limiting membrane (OLM) formed by the outer extremities of the Müller glia processes (Fig. 8B ii). To verify that the AGO2 mRNA was indeed expressed in the OLM, co-labelling with glutamine synthase (Müller glia marker) was performed showing distinct AGO2-Müller glia colocalization within the OLM and further revealing AGO2 mRNA expression along the processes of Müller glia traversing the ONL (Fig. 8B ii).

Immunohistochemistry for AGO2 corroborated the changes observed at gene level, primarily showing that AGO2 is expressed in the GCL and INL where its expression increases following photo-oxidative damage (Fig. 8C ii). In addition, AGO2 protein was expressed in the photoreceptor segments and the PD dependent increase here was evident in both the superior and inferior retina, but not at the lesion site (likely due to a focal loss of photoreceptor segments here) (Fig. 8C ii). Colabelling of $\mathrm{AGO} 2$ protein and Müller glia (using a Müller glia reporter mouse strain) showed distinct colocalization within the OLM, along the Müller glia processes traversing the OLM, and a more pronounced localization with the cell bodies of Müller glia in the INL in the superior retina compared to the other retinal sites examined (Fig. 8C ii). AGO expression changes across the retina were also depicted graphically highlighting the changes in the photoreceptor segments and within the central region of the INL (Fig. 8D i and ii). Finally, changes in bulk $\mathrm{AGO} 2$ protein expression were measured by western blot indicating that an increase of approximately 3 -fold occurs following $\mathrm{PD}(P<0.05$, Fig. 8E i and ii). 


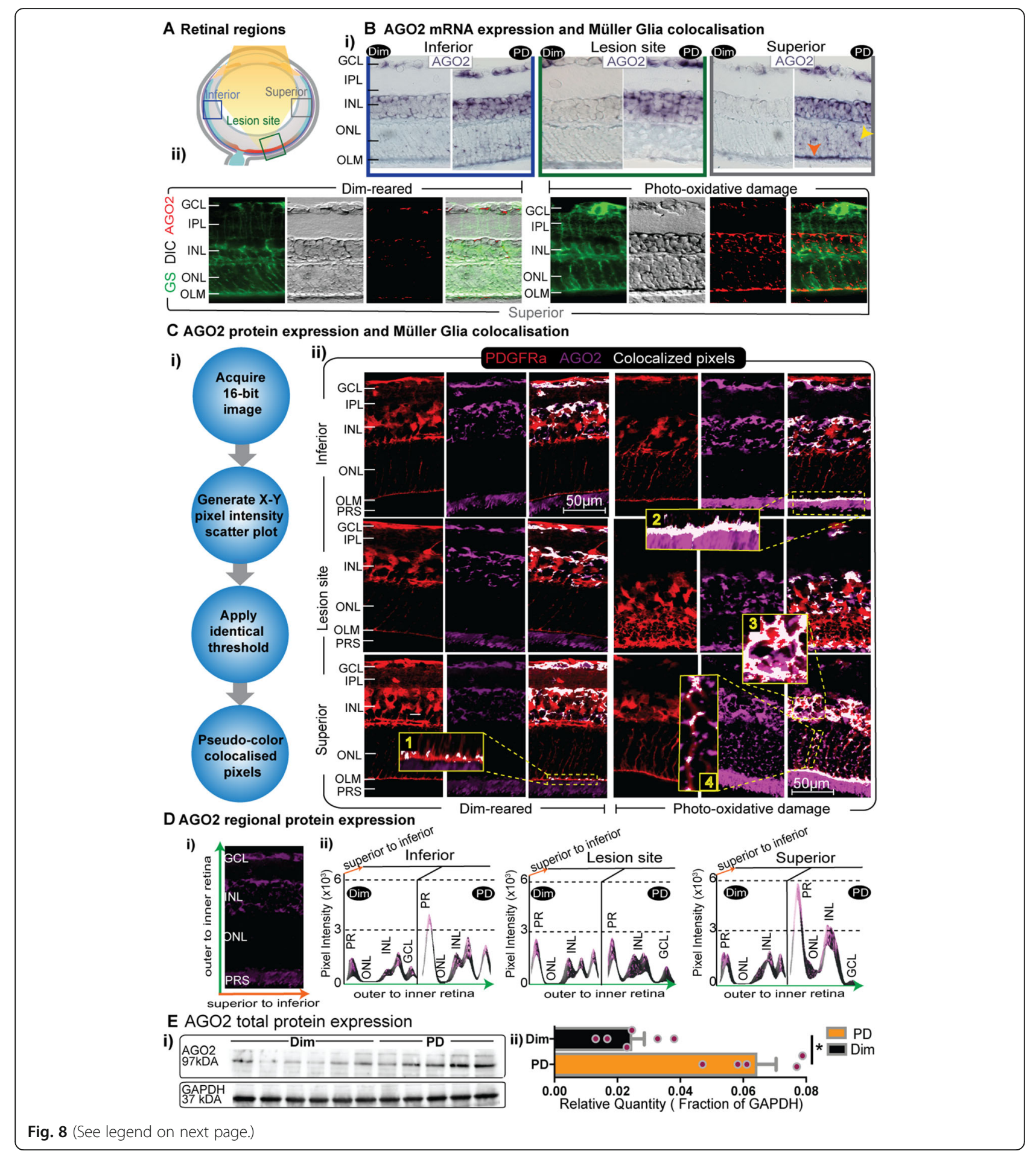


(See figure on previous page.)

Fig. 8 AGO2 gene and protein expression changes following PD. (A) Diagram indicating retinal regions where histological measures were taken. Lesion site refers to the area most damaged by PD. (B) (i) AGO2 in situ hybridization in dim and PD retinas at the three retinal sites indicated in A. AGO2 mRNA increased at all three locations and is distributed across the GCL, INL in the inferior retina and lesion site. In the superior retina, AGO2 mRNA expression is also visible within the ONL (yellow arrow) and the OLM (orange arrow). (ii) Co-labelling of AGO2 mRNA and glutamine synthetase in the superior retina showing colocalization along the OLM and Müller glia processes. Gray micrographs are DIC images of AGO2 in situ hybridization (as shown in i). Red labelling are pseudo-coloured pixels corresponding to the area positive for AGO2 labelling (dark spots in the adjacent DIC image). (C) (i) Image analysis pipeline used for colocalization analysis. (ii) Immunohistochemistry showed AGO2 protein expression is confined within the GCL, INL and photoreceptor segments in dim retinas. Following PD, AGO2 protein expression is elevated within the INL and photoreceptor segments. Co-localization of AGO2 labelling with Müller glia visualized using a reporter mouse strain showed distinct colocalization along the inferior and superior OLM (inset 2), Müller glia processes (inset 4) and Müller glia cell bodies (inset 3). In the absence of PD limited colocalization is seen in the superior retina (inset 1). (D) (i) Axis description for plots shown in ii. (ii) AGO2 protein expression profile quantified across retinal layers and depicted as pixel intensity (y-axis), along the outer to inner retinal direction (green $x$-axis) and superior to inferior (orange z-axis). (E) (i) AGO2 western blot and corresponding GAPDH loading control. (ii) GAPDH-normalized densitometry values for AGO2 (Error bars show SEM, * $P<0.05$, Student's t-test)

Taken together, these data indicate that AGO2 has a pan-retinal expression primarily within the nuclear layers of the retina and the photoreceptor segments. Photo-oxidative damage induces a dynamic increase both AGO2 gene and protein expression and some fraction of this increase occurs in Müller glia, most prominently in at the OLM.

\section{Discussion}

miRNAs are the most studied non-coding RNA in the central nervous system (CNS) [69] including the retina [60]. Despite this, the specific miRNAs required to maintain retinal homeostasis or to respond to retinal degeneration have not been identified or well-studied. Studies characterizing the retinal miRnome under homeostatic conditions have utilized small RNA sequencing technology to investigate the total retinal miRNA expression profile with high resolution and sensitivity [70]. We built on these previous findings by performing HTS of the global retinal mRNA and miRNA in both the healthy retina and degenerating retina. We found that both global miRNA and mRNA expression profiles are highly regulated in response to PD. Further, we showed that several inflammatory-related pathways are highly enriched and highlight key mRNAs integral to these pathways. We extended this study by utilizing AGO2 HITS-CLIP, to allow the in vivo identification of the functionally active AGO2-bound mRNAs and miRNAs. This enabled us to characterize the functional retinal miRnome. We observed no change in AGO2-bound miRNAs in response to $\mathrm{PD}$, but interestingly observed a change in the AGO2-bound mRNA targets suggesting a shift in the action site of the miRNA silencing machinery. This mechanism likely underpins the role miR-124$3 p$ plays in retinal degeneration as we have previously shown translocation of miR-124-3p through extracellular vesicles $(\mathrm{EV})[14,71]$ between retinal cell layers where miR-124-3p may modulate a new subset of distinct targets. Further analysis using motif enrichment of AGO2- bound mRNAs revealed a change in the seed region binding activity of the highly expressed miR-124-3p following PD. Analysis of AGO2 location showed expression in distinct cell types with histological staining demonstrating that AGO2 mRNA and protein accumulation appears to be expressed within Müller glia - a likely destination for miR-124-3p following the degeneration-dependent translocation of miR-124-3p as we have previously reported [14]. Moreover, the AGO2bound miRNAs and mRNAs were linked to key pathways already identified as regulators of human AMD pathogenesis, such as the complement cascade, immune response and cell death $[17,18]$. Taken together, these data demonstrate a dynamic interaction of the retinal AGO2 miRnome with its targetome which is influenced by the tissue environment. Therefore, our data provide important new insight into miRNA functionality during neurodegeneration, and identification of multiple miRNA-mRNA interactions of biological importance in retinal degenerations.

\section{miRNA expression is altered as a consequence of photoreceptor specific retinal degeneration}

Previous reports have suggested that the vast majority of cellular miRnomes are comprised of only a few highly abundant miRNAs [72-75]. We used HTS to provide a snapshot of the retinal mRNA and miRNA composition and revealed that approximately $85 \%$ of the retinal miRnome consists of only 20 different miRNAs in both the healthy and degenerating retina. This includes key members of the photoreceptor cluster miR-183/96/182, which are involved in the development and homeostasis of photoreceptor cells [76] and miR-124-3p, a neuronallyenriched miRNA that plays a role in neuron homeostasis [31-34]. This data suggests that regulation of neuronal homeostasis plays an overarching role not only in the healthy, but also the degenerating retina. It is therefore not surprising that the dim and PD AGO2-bound miRnomes majorly comprised miRNAs that are known to 
play a role in retinal development and homeostasis, such as the photoreceptor cluster miR-183/96/182, miR-204$5 p$, let-7a-5p and miR-124-3p. In fact, we have previously characterized miR-124-3p, and shown that supplementation of miR-124-3p during retinal damage preserves retinal function, protects against photoreceptor death and reduces inflammation [14]. miRNet analysis showed that AGO2-bound miR-124-3p and miR181a-5p (another highly-enriched retinal miRNA [77]) displayed extensive AGO2-bound mRNA target networks, further strengthening the notion that only a few highly enriched miRNAs are responsible for the majority of regulation of a dynamic group of mRNA targets [7883]. However, despite significant changes in global miRNA expression in the damaged retina, we observed no significant change to the AGO2-bound miRnome. It is possible that the globally altered miRnome reflects a miRNA transcription and processing state that is either are not functional, e.g. those miRNAs are not incorporated into $\mathrm{AGO} 2$, or are operating via a non-canonical miRNA pathway $[84,85]$. Further studies in this area are required to explore the non-canonical miRNA pathways in retinal degenerations.

\section{miRNA are important for maintaining retinal homeostasis} and regulating innate immunity

GO term and pathway analyses of the global mRNA HTS showed that photoreceptor maintenance and visual cycle were highly enriched in both healthy control and degenerating retina. This was also true for the AGO2bound mRNAs in both dim and PD, again indicating that maintenance of the visual system remains a regulatory priority in the retina. However, the global mRNA HTS also revealed that many of the pathways enriched in PD are involved in retinal inflammation [18]. Similarly, GO term and pathway analysis of the differentially AGO2-bound mRNAs showed significant enrichment of pathways of the immune response, regulation of defense, regulation of immune system processes and response to stress. Further, we demonstrated that there was a significant association with visual processes when it came to down-regulated targets. Up-regulated targets were involved in the inflammatory and stress responses. These findings are not unexpected, as these pathways have previously been strongly implicated to play a role in the progression of retinal degeneration [42, 86-89]. However, what we have demonstrated here is the influence that miRNA have on retinal inflammation in addition to dampening their influence on visual transduction in a stressed environment.

The immune response, particularly the innate immune response, is well-established to influence the progression of retinal degenerations (reviewed in [18]). Pathways involved in the innate system such as the interleukin and cytokine release were also significantly enriched in our differentially expressed dataset. Another highly represented pathway in our dataset was the complement system, which has been previously identified as a major instigator of inflammatory dysregulation in AMD [8689]. Given this high immune pathway representation in this data, determining the miRNA binding sites within these miRNAs may lead to advances in potential therapeutic options targeting key inflammatory components involved in the degenerating retina.

\section{miRNA binding sites change in response to retinal degenerations}

To understand the change in miRNA binding sites in response to retinal degenerations, we used sequence motif enrichment analysis within the 3' UTRs of AGO2bound mRNAs identified by HITS-CLIP. We demonstrated that the most enriched motif in PD were the reverse complementary canonical seed sequences of miR-124-3p indicative of high miR-124-3p binding and activity in the retina during degeneration. Interestingly, dim retinas showed a different enriched motif and with the actual seed sequence of miR-124-3p determined to be the most enriched. While understanding the biological relevance of this interaction is outside the scope of this work, we suggest that it may point to a selfregulatory system whereby miR-124-3p is being bound to itself under homeostatic conditions by its passenger strand. During the process of miRNA maturation, miRNA are loaded onto AGO2 in their duplex form before being unwound to generate a mature RISC [90]. We have previously shown miR-124-3p to be largely concentrated along the OLM in healthy normal retina, before translocating to the inner retina following photoreceptor specific retinal damage $[14,71]$. It may be possible that miR-124-3p sits in a reservoir as a miRNA duplex and is more preferentially unwound under duress [91]. An alternative hypothesis is that miR-124-3p is present naturally where it is produced and requires an upregulation of AGO2 to be unwound. Extensive research is needed to uncover the complexities of miR-124-3p biogenesis and function and its potential alteration in activity during health and disease.

It is apparent, however, that there is a change in binding behavior of active miRNA following retinal damage with miR-124-3p activity enriched during PD. We postulate that miRNA activity in the damaged retina is different compared to the homeostatic state as our data demonstrates that the miRNA targets differ to regulate more inflammatory processes when the retina is under duress. It is likely that retinal degenerations cause existing miRNA populations to regulate different targets rather than transcribe novel miRNAs, which has been suggested in previous publications [92]. This study is the 
first indication that such a regulatory system also operates in the retina. The alternative regulation of target mRNAs is likely due to a movement of miRNA activity within the retina in response to degeneration [14, 71, 93]. As aforementioned, our previous studies have shown miR-124 to move to the Müller glia to regulate the expression of CCL2 upon damage onset [14]. We have demonstrated that this movement is, in part, mediated by EV, where miR-124 expression remains stagnant in the retina following EV biogenesis inhibition [14, 71]. This potential movement is further corroborated by the alternative labelling of $\mathrm{AGO} 2$ we have demonstrated here. AGO2 appears to concentrate along the Müller glial end feet in the OLM of the inferior and peripheral regions of the retina where there is less tissue degeneration from photo-oxidative damage. However, at the damage site, AGO2 expression seems to be more heavily expressed within the INL, including within the Müller glia bodies. Taken together, this may be indicative of a tightly balanced glia-to-neuron transfer of information as a means to combat against neurodegenerative insults and maintain homeostasis in the retina [14, 93, 94].

An alternative explanation to these observed differences could be that canonical miRNA biogenesis might not be the only pathway contributing to retinal homeostasis and retinal degenerations. Work in the field is beginning to shift focus towards miRNA binding events that occur outside of the 3' UTR [95]. This might explain the difference in gene expression between global HTS and HITS-CLIP. Further analysis of the enriched peaks in our data may reveal binding sites in the coding region or the $5^{\prime}$ UTR. It is further possible that miRNA binding to its target is regulated by wobble or bulge nucleotides [96-98] or RNA modifications such as 6methyladenosine, 5-methylcytosine or pseudouridine. Such alternative regulation could be indicative of noncanonical miRNA biogenesis in retinal degenerations and requires further exploration.

\section{Conclusions}

In conclusion, our data suggests that miRNA are actively involved in regulating key genes and biological pathways involved in retinal degeneration. Whilst the AGO2bound miRNA accumulation did not change significantly between healthy and damaged retinas, we demonstrate that there is a dynamic change in the miRNA target landscape mediated by favoring an extended seed sequence. Further, our data provide support to the notion that a change in miRNA targeting under stress is the result of miRNA movement throughout the retinal layers. Additional research into this mechanism will help uncover the intricacies of miRNA biology in neurodegenerative disorders.

\section{Abbreviations}

3' UTR: 3' untranslated region; 5' UTR: 5' untranslated region; AGO: argonaute; AGO2: argonaute 2; AMD: age-related macular degeneration; BWB: bead wash buffer; CCl2: chemokine C-C motif ligand 2; CNS: central nervous system; $\mathrm{CO}_{2}$ : carbon dioxide; DIG: digoxigenin; Dim: dim-reared; EGTA: ethylene glycol-bis( $\beta$-aminoethyl ether)-N,N,N',N'-tetraacetic acid; GCL: ganglion cell layer; GO: gene ontology; GSEA: gene set enrichment analysis; HITS-CLIP: high-throughput sequencing following cross-linking immunoprecipitation; HTS: high-throughput sequencing; lgG: immunoglobulin G; INL: inner nuclear layer; LED: light-emitting diode; miRNA: microRNA; miRnome: miRNA transcriptome; mRNA: messenger RNA; ncRNA: non-coding RNA; OLM: outer limiting membrane; ONL: outer nuclear layer;

PBS: phosphate buffered solution; PCA: principal component analysis; PCR: polymerase chain reaction; PD: photo-oxidative damage; PNK: polynucleotide kinase; RFP: red fluorescent protein; RGC: retinal ganglion cells; RIN: RNA integrity number; RISC: RNA-induced silencing complex; RNA: ribonucleic acid; Rock2: rho-associated protein kinase 2; RPM: revolutions per minute; RT: room temperature; scRNAseq: single-cell RNA sequencing; Targetome: target transcriptome; TTS: transcription termination site; UV: ultraviolet

\section{Supplementary Information}

The online version contains supplementary material available at https://doi. org/10.1186/s13024-021-00478-9.

Additional file 1 Fig. S1. Volcano plots of the differentially expressed mRNA (A) and miRNA (B) in the global retina dataset.

Additional file 2 Fig. S2. Intragenic distribution of the $\mathrm{AGO} 2$ clusters within mRNAs.

Additional file 3 Fig. S3. Distribution of miR-124-3p AGO2-bound targets in the retina.

Additional file 4 Table S1. HTS data. Table S2. HTS miRNA data. Table S3. AGO2 HITS-CLIP mRNA data. Table S5. Significantly enriched pathways in global RNA between dim and PD retinas. Table S6. Up-regulated AGO2-bound mRNA. Table S7. Down-regulated AGO2-bound mRNA. Table S8. Up-regulated AGO2-bound mRNA GO - Molecular Function and Cellular Component. Table S9. Down-regulated AGO2-bound mRNA GO - Molecular Function and Cellular Component. Table S10. AGO2bound mRNA predicted to bind to miR-124-3p.

Acknowledgements

Not applicable.

Authors' contributions

Conceptualization, J.A.C., A.V.C. and R.N.; Methodology, J.A.C., A.V.C., R.N. K.P. and K.H.; Data analysis, J.A.C., A.V.C., Z.F. and H.P.; Investigation, J.A.C., A.V.C. and Y.W.; Writing - Original Draft, J.A.C., A.V.C., and R.N.; Writing - Review and Editing, J.A.C., R.N. and Y.W.; Supervision, R.N.; Funding Acquisition, R. N, J.A.C., M.R. and J.P. All authors read and approved the final manuscript.

\section{Authors' information}

Not applicable.

\section{Funding}

This work would not have been possible without the support of the National Health and Medical Research Council of Australia (NHMRC: 1127705, NHMRC: 202239), Retina Australia, The Gordon and Gretel Bootes Foundation and The ANU Translational Fellowship.

\section{Availability of data and materials}

The datasets supporting the conclusions of this article are available on the Sequence Read Archive (PRJNA606092) as part of the National Center for Biotechnology Information (NCBI). Processed RNA-seq data can be interactively explored at: https://genedatasets.shinyapps.io/ARMMI/ 


\section{Declarations}

\section{Ethics approval and consent to participate}

All animal experiments were conducted in accordance with the ARVO Statement for Use of Animals in Ophthalmic and Vision Research and with approval from the ANU Animal Experimentation Ethics Committee (Ethics ID: A2014/56).

\section{Consent for publication}

Not applicable.

\section{Competing interests}

The authors declare no competing interests.

\section{Author details}

${ }^{1}$ Eccles Institute of Neuroscience, The John Curtin School of Medical Research, College of Health and Medicine, The Australian National University, Acton, Canberra, ACT 2601, Australia. ${ }^{2}$ The Australian National University Medical School, College of Health and Medicine, Canberra, ACT 2601, Australia. ${ }^{3}$ The ANU Bioinformatics Consultancy, The John Curtin School of Medical Research, College of Health and Medicine, The Australian National University, Acton, Canberra, ACT 2601, Australia. ${ }^{4}$ School of Biomedical Sciences, The University of Melbourne, Parkville, Victoria 3010, Australia. ${ }^{5}$ Faculty of Science and Technology, University of Canberra, Bruce, ACT 2617, Australia. ${ }^{6}$ ACRF Department of Cancer Biology and Therapeutics, The John Curtin School of Medical Research, College of Health and Medicine, The Australian National University, Acton, Canberra, ACT 2601, Australia. ${ }^{7}$ School of Biological Sciences Queen's University Belfast, Belfast BT9 5DL, Northern Ireland.

\section{Received: 11 May 2021 Accepted: 3 August 2021}

Published online: 31 August 2021

\section{References}

1. Krol J, Busskamp V, Markiewicz I, Stadler MB, Ribi S, Richter J, et al. Characterizing light-regulated retinal microRNAs reveals rapid turnover as a common property of neuronal microRNAs. Cell. 2010;141(4):618-31. https:// doi.org/10.1016/j.cell.2010.03.039.

2. Elbashir SM, Lendeckel W, Tuschl T. RNA interference is mediated by 21and 22-nucleotide RNAs. Genes Dev. 2001;15(2):188-200. https://doi.org/1 $0.1101 /$ gad.862301.

3. Elbashir SM, Martinez J, Patkaniowska A, Lendeckel W, Tuschl T. Functional anatomy of siRNAs for mediating efficient RNAi in Drosophila melanogaster embryo lysate. EMBO J. 2001;20(23):6877-88. https://doi.org/10.1093/ emboj/20.23.6877.

4. Hammond SM, Bernstein E, Beach D, Hannon GJ. An RNA-directed nuclease mediates post-transcriptional gene silencing in Drosophila cells. Nature. 2000:404(6775):293-6. https://doi.org/10.1038/35005107.

5. Martinez J, Patkaniowska A, Urlaub H, Luhrmann R, Tuschl T. Single-stranded antisense siRNAs guide target RNA cleavage in RNAi. Cell. 2002;110(5):56374. https://doi.org/10.1016/S0092-8674(02)00908-X.

6. Nykanen A, Haley B, Zamore PD. ATP requirements and small interfering RNA structure in the RNA interference pathway. Cell. 2001;107(3):309-21. https://doi.org/10.1016/S0092-8674(01)00547-5.

7. Schwarz DS, Hutvagner G, Haley B, Zamore PD. Evidence that siRNAs function as guides, not primers, in the Drosophila and human RNAi pathways. Mol Cell. 2002;10(3):537-48. https://doi.org/10.1016/S1097-2 765(02)00651-2.

8. Lewis BP, Burge CB, Bartel DP. Conserved seed pairing, often flanked by adenosines, indicates that thousands of human genes are microRNA targets. Cell. 2005;120(1):15-20. https://doi.org/10.1016/j.cell.2004.12.035.

9. Bazzini AA, Lee MT, Giraldez AJ. Ribosome profiling shows that miR-430 reduces translation before causing mRNA decay in zebrafish. Science. 2012; 336(6078):233-7. https://doi.org/10.1126/science.1215704.

10. Djuranovic S, Nahvi A, Green R. miRNA-mediated gene silencing by translational repression followed by mRNA deadenylation and decay. Science. 2012;336(6078):237-40. https://doi.org/10.1126/science.1215691.

11. Friedman RC, Farh KK, Burge CB, Bartel DP. Most mammalian mRNAs are conserved targets of microRNAs. Genome Res. 2009;19(1):92-105.

12. Bartel DP. MicroRNAs: genomics, biogenesis, mechanism, and function. Cell. 2004;116(2):281-97. https://doi.org/10.1016/S0092-8674(04)00045-5.
13. Bartel DP, Chen CZ. Micromanagers of gene expression: the potentially widespread influence of metazoan microRNAs. Nat Rev Genet. 2004;5(5): 396-400. https://doi.org/10.1038/nrg1328.

14. Chu-Tan JA, Rutar M, Saxena K, Aggio-Bruce R, Essex RW, Valter K, et al. MicroRNA-124 dysregulation is associated with retinal inflammation and photoreceptor death in the degenerating retina. Invest Ophthalmol Vis Sci. 2018;59(10):4094-105. https://doi.org/10.1167/iovs.18-24623.

15. Lukiw WJ, Surjyadipta B, Dua P, Alexandrov PN. Common micro RNAs (miRNAs) target complement factor $\mathrm{H}(\mathrm{CFH})$ regulation in Alzheimer's disease (AD) and in age-related macular degeneration (AMD). Int J Biochem Mol Biol. 2012:3(1):105-16.

16. Qiu L, Tan EK, Zeng L. microRNAs and Neurodegenerative Diseases. Adv Exp Med Biol. 2015;888:85-105. https://doi.org/10.1007/978-3-319-22671-2 6.

17. Ambati J, Ambati BK, Yoo SH, lanchulev S, Adamis AP. Age-related macular degeneration: etiology, pathogenesis, and therapeutic strategies. Surv Ophthalmol. 2003;48(3):257-93. https://doi.org/10.1016/S0039-6257(03)0003 $0-4$.

18. Ambati J, Atkinson JP, Gelfand BD. Immunology of age-related macular degeneration. Nat Rev Immunol. 2013;13(6):438-51. https://doi.org/10.1038/ nri3459.

19. Beatty S, Koh H, Phil M, Henson D, Boulton M. The role of oxidative stress in the pathogenesis of age-related macular degeneration. Surv Ophthalmol. 2000;45(2):115-34. https://doi.org/10.1016/S0039-6257(00)00140-5.

20. Hollyfield JG, Bonilha VL, Rayborn ME, Yang X, Shadrach KG, Lu L, et al. Oxidative damage-induced inflammation initiates age-related macular degeneration. Nat Med. 2008;14(2):194-8. https://doi.org/10.1038/nm1 709.

21. Hollyfield JG, Perez VL, Salomon RG. A hapten generated from an oxidation fragment of docosahexaenoic acid is sufficient to initiate age-related macular degeneration. Mol Neurobiol. 2010;41(2-3):290-8. https://doi.org/1 0.1007/s12035-010-8110-z.

22. Salomon RG, Hong L, Hollyfield JG. Discovery of carboxyethylpyrroles (CEPs): critical insights into AMD, autism, cancer, and wound healing from basic research on the chemistry of oxidized phospholipids. Chem Res Toxicol. 2011;24(11):1803-16. https://doi.org/10.1021/tx200206v.

23. Berber $\mathrm{P}$, Grassmann $\mathrm{F}$, Kiel C, Weber BH. An eye on age-related macular degeneration: the role of MicroRNAs in disease pathology. Mol Diagn Ther. 2017:21(1):31-43. https://doi.org/10.1007/s40291-016-0234-z.

24. Bhattacharjee S, Zhao Y, Dua P, Rogaev El, Lukiw WJ. microRNA-34aMediated Down-Regulation of the Microglial-Enriched Triggering Receptor and Phagocytosis-Sensor TREM2 in Age-Related Macular Degeneration. PLoS One. 2016:11(3):e0150211.

25. Ertekin S, Yildirim O, Dinc E, Ayaz L, Fidanci SB, Tamer L. Evaluation of circulating miRNAs in wet age-related macular degeneration. Mol Vis. 2014; 20:1057-66.

26. Grassmann F, Schoenberger PG, Brandl C, Schick T, Hasler D, Meister G, et al A circulating microrna profile is associated with late-stage neovascular agerelated macular degeneration. PLoS One. 2014;9(9):e107461. https://doi. org/10.1371/journal.pone.0107461.

27. Menard C, Rezende FA, Miloudi K, Wilson A, Tetreault N, Hardy P, et al. MicroRNA signatures in vitreous humour and plasma of patients with exudative AMD. Oncotarget. 2016;7(15):19171-84. https://doi.org/10.18632/ oncotarget.8280

28. Murad N, Kokkinaki M, Gunawardena N, Gunawan MS, Hathout Y, Janczura $\mathrm{KJ}$, et al. miR-184 regulates ezrin, LAMP-1 expression, affects phagocytosis in human retinal pigment epithelium and is downregulated in age-related macular degeneration. FEBS J. 2014;281(23):5251-64. https://doi.org/1 $0.1111 /$ febs.13066

29. Szemraj M, Bielecka-Kowalska A, Oszajca K, Krajewska M, Gos R, Jurowski P, et al. Serum MicroRNAs as potential biomarkers of AMD. Med Sci Monit. 2015;21:2734-42. https://doi.org/10.12659/MSM.893697.

30. Zhou Q, Anderson C, Zhang H, Li X, Inglis F, Jayagopal A, et al. Repression of choroidal neovascularization through actin cytoskeleton pathways by microRNA-24. Mol Ther. 2014;22(2):378-89. https://doi.org/10.1038/mt.2 013.243.

31. Conaco C, Otto S, Han JJ, Mandel G. Reciprocal actions of REST and a microRNA promote neuronal identity. Proc Natl Acad Sci U S A. 2006;103(7): 2422-7. https://doi.org/10.1073/pnas.0511041103.

32. Lagos-Quintana M, Rauhut R, Yalcin A, Meyer J, Lendeckel W, Tuschl T. Identification of tissue-specific microRNAs from mouse. Curr Biol. 2002;12(9): 735-9. https://doi.org/10.1016/S0960-9822(02)00809-6. 
33. Lim LP, Lau NC, Garrett-Engele P, Grimson A, Schelter JM, Castle J, et al. Microarray analysis shows that some microRNAs downregulate large numbers of target mRNAs. Nature. 2005;433(7027):769-73. https://doi.org/ 0.1038 /nature03315.

34. Makeyev EV, Zhang J, Carrasco MA, Maniatis T. The MicroRNA miR-124 promotes neuronal differentiation by triggering brain-specific alternative pre-mRNA splicing. Mol Cell. 2007;27(3):435-48. https://doi.org/10.1016/j. molcel.2007.07.015.

35. Chi SW, Zang JB, Mele A, Darnell RB. Argonaute HITS-CLIP decodes microRNA-mRNA interaction maps. Nature. 2009;460(7254):479-86. https:// doi.org/10.1038/nature08170

36. Jensen KB, Darnell RB. CLIP: crosslinking and immunoprecipitation of in vivo RNA targets of RNA-binding proteins. Methods Mol Biol. 2008;488:85-98. https://doi.org/10.1007/978-1-60327-475-3_6.

37. Licatalosi DD, Mele A, Fak JJ, Ule J, Kayikci M, Chi SW, et al. HITS-CLIP yields genome-wide insights into brain alternative RNA processing. Nature. 2008; 456(7221):464-9. https://doi.org/10.1038/nature07488.

38. Ule J, Jensen K, Mele A, Darnell RB. CLIP: a method for identifying proteinRNA interaction sites in living cells. Methods. 2005;37(4):376-86. https://doi. org/10.1016/j.ymeth.2005.07.018.

39. Ule J, Jensen KB, Ruggiu M, Mele A, Ule A, Darnell RB. CLIP identifies Novaregulated RNA networks in the brain. Science. 2003;302(5648):1212-5. https://doi.org/10.1126/science.1090095.

40. Yeo GW, Coufal NG, Liang TY, Peng GE, Fu XD, Gage FH. An RNA code for the FOX2 splicing regulator revealed by mapping RNA-protein interactions in stem cells. Nat Struct Mol Biol. 2009;16(2):130-7. https://doi.org/10.1038/ nsmb.1545.

41. Petri R, Malmevik J, Fasching $L$, Akerblom M, Jakobsson J. miRNAs in brain development. Exp Cell Res. 2014;321(1):84-9. https://doi.org/10.1016/j. yexcr.2013.09.022.

42. Natoli R, Jiao H, Barnett NL, Fernando N, Valter K, Provis JM, et al. A model of progressive photo-oxidative degeneration and inflammation in the pigmented C57BL/6J mouse retina. Exp Eye Res. 2016;147:114-27. https:// doi.org/10.1016/j.exer.2016.04.015.

43. Moore MJ, Zhang C, Gantman EC, Mele A, Darnell JC, Darnell RB. Mapping Argonaute and conventional RNA-binding protein interactions with RNA at single-nucleotide resolution using HITS-CLIP and CIMS analysis. Nat Protoc. 2014;9(2):263-93. https://doi.org/10.1038/nprot.2014.012.

44. Li H, Durbin R. Fast and accurate long-read alignment with burrowswheeler transform. Bioinformatics. 2010;26(5):589-95. https://doi.org/10.1 093/bioinformatics/btp698.

45. Li H, Handsaker B, Wysoker A, Fennell T, Ruan J, Homer N, et al. The sequence alignment/map format and SAMtools. Bioinformatics. 2009:25(16): 2078-9. https://doi.org/10.1093/bioinformatics/btp352.

46. Liao Y, Smyth GK, Shi W. featureCounts: an efficient general purpose program for assigning sequence reads to genomic features. Bioinformatics. 2014:30(7):923-30. https://doi.org/10.1093/bioinformatics/btt656.

47. Law CW, Chen Y, Shi W, Smyth GK. voom: Precision weights unlock linear model analysis tools for RNA-seq read counts. Genome Biol. 2014;15(2):R29.

48. Ritchie ME, Phipson B, Wu D, Hu Y, Law CW, Shi W, et al. limma powers differential expression analyses for RNA-sequencing and microarray studies. Nucleic Acids Res. 2015;43(7):e47.

49. Robinson MD, Oshlack A. A scaling normalization method for differential expression analysis of RNA-seq data. Genome Biol. 2010;11(3):R25. https:// doi.org/10.1186/gb-2010-11-3-r25.

50. Kozomara A, Griffiths-Jones S. miRBase: annotating high confidence microRNAs using deep sequencing data. Nucleic Acids Res. 2014; 42(Database issue):D68-73. https://doi.org/10.1093/nar/gkt1181.

51. Fan Y, Siklenka K, Arora SK, Ribeiro P, Kimmins S, Xia J. miRNet - dissecting miRNA-target interactions and functional associations through networkbased visual analysis. Nucleic Acids Res. 2016;44(W1):W135-41. https://doi. org/10.1093/nar/gkw288.

52. Eden E, Navon R, Steinfeld I, Lipson D, Yakhini Z. GOrilla: a tool for discovery and visualization of enriched $\mathrm{GO}$ terms in ranked gene lists. BMC Bioinformatics. 2009;10(1):48. https://doi.org/10.1186/1471-2105-10-48,

53. Wu D, Smyth GK. Camera: a competitive gene set test accounting for intergene correlation. Nucleic Acids Res. 2012;40(17):e133. https://doi.org/10.1 093/nar/gks461.

54. Macosko EZ, Basu A, Satija R, Nemesh J, Shekhar K, Goldman M, et al. Highly parallel genome-wide expression profiling of individual cells using Nanoliter droplets. Cell. 2015;161(5):1202-14. https://doi.org/10.1016/j.cell.2015.05.002.
55. Wickham H. ggplot2: Elegant Graphics for Data Analysis Springer-Verlag New York; 2016

56. R Development Core team. R: a language and environment for statistical computing. Vienna, Austria: R Foundation for Statistical Computing; 2017.

57. Cornish EE, Madigan MC, Natoli R, Hales A, Hendrickson AE, Provis JM. Gradients of cone differentiation and FGF expression during development of the foveal depression in macaque retina. Vis Neurosci. 2005;22(4):447-59. https://doi.org/10.1017/S0952523805224069.

58. Schneider CA, Rasband WS, Eliceiri KW. NIH image to ImageJ: 25 years of image analysis. Nat Methods. 2012;9(7):671-5. https://doi.org/10.1038/ nmeth.2089.

59. Bolte S, Cordelieres FP. A guided tour into subcellular colocalization analysis in light microscopy. J Microsc. 2006;224(Pt 3):213-32. https://doi.org/1 0.1111/j.1365-2818.2006.01706.x.

60. Karali M, Banfi S. Non-coding RNAs in retinal development and function. Hum Genet. 2019;138(8-9):957-71. https://doi.org/10.1007/s00439-018-1931y.

61. Karali M, Peluso I, Gennarino VA, Bilio M, Verde R, Lago G, et al. miRNeye: a microRNA expression atlas of the mouse eye. BMC Genomics. 2010;11:715.

62. Karali M, Peluso I, Marigo V, Banfi S. Identification and characterization of microRNAs expressed in the mouse eye. Invest Ophthalmol Vis Sci. 2007; 48(2):509-15. https://doi.org/10.1167/iovs.06-0866.

63. Xiang L, Chen XJ, Wu KC, Zhang CJ, Zhou GH, Lv JN, et al. miR-183/96 plays a pivotal regulatory role in mouse photoreceptor maturation and maintenance. Proc Natl Acad Sci U S A. 2017;114(24):6376-81. https://doi. org/10.1073/pnas.1618757114.

64. Xu S, Witmer PD, Lumayag S, Kovacs B, Valle D. MicroRNA (miRNA) transcriptome of mouse retina and identification of a sensory organ-specific miRNA cluster. J Biol Chem. 2007;282(34):25053-66. https://doi.org/10.1074/ jbc.M700501200.

65. Liberzon A, Subramanian A, Pinchback R, Thorvaldsdottir $H$, Tamayo $P$, Mesirov JP. Molecular signatures database (MSigDB) 3.0. Bioinformatics. 2011;27(12):1739-40. https://doi.org/10.1093/bioinformatics/btr260.

66. Subramanian A, Tamayo P, Mootha VK, Mukherjee S, Ebert BL, Gillette MA, et al. Gene set enrichment analysis: a knowledge-based approach for interpreting genome-wide expression profiles. Proc Natl Acad Sci U S A 2005;102(43):15545-50. https://doi.org/10.1073/pnas.0506580102.

67. Rutar M, Natoli R, Valter K, Provis JM. Early focal expression of the chemokine $\mathrm{C} \mathrm{Cl} 2$ by Muller cells during exposure to damage-inducing bright continuous light. Invest Ophthalmol Vis Sci. 2011;52(5):2379-88. https://doi. org/10.1167/iovs.10-6010.

68. Yamaguchi M, Nakao S, Arima M, Wada I, Kaizu Y, Hao F, et al. Rho-kinase/ ROCK as a potential drug target for vitreoretinal diseases. J Ophthalmol. 2017;2017:8543592.

69. Cao DD, Li L, Chan WY. MicroRNAs: Key Regulators in the Central Nervous System and Their Implication in Neurological Diseases. Int J Mol Sci. 2016; 17(6):842.

70. Karali M, Persico M, Mutarelli M, Carissimo A, Pizzo M, Singh Marwah V, et al. High-resolution analysis of the human retina miRNome reveals isomiR variations and novel microRNAs. Nucleic Acids Res. 2016;44(4):1525-40. https://doi.org/10.1093/nar/gkw039.

71. Wooff Y, Cioanca AV, Chu-Tan JA, Aggio-Bruce R, Schumann U, Natoli R. Small-medium extracellular vesicles and their miRNA cargo in retinal health and degeneration: mediators of homeostasis, and vehicles for targeted gene therapy. Front Cell Neurosci. 2020;14:160. https://doi.org/10.3389/ fncel.2020.00160.

72. Couzin J. MicroRNAs make big impression in disease after disease. Science. 2008;319(5871):1782-4. https://doi.org/10.1126/science.319.5871.1782.

73. Meola N, Gennarino VA, Banfi S. microRNAs and genetic diseases. Pathogenetics. 2009;2(1):7.

74. Sanuki R, Onishi A, Koike C, Muramatsu R, Watanabe S, Muranishi Y, et al. miR-124a is required for hippocampal axogenesis and retinal cone survival through Lhx2 suppression. Nat Neurosci. 2011;14(9):1125-34. https://doi. org/10.1038/nn.2897.

75. Wienholds E, Kloosterman WP, Miska E, Alvarez-Saavedra E, Berezikov E, de

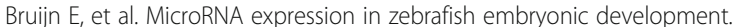
Science. 2005;309(5732):310-1. https://doi.org/10.1126/science.1114519.

76. Busskamp V, Krol J, Nelidova D, Daum J, Szikra T, Tsuda B, et al. miRNAs 182 and 183 are necessary to maintain adult cone photoreceptor outer segments and visual function. Neuron. 2014;83(3):586-600. https://doi.org/1 0.1016/j.neuron.2014.06.020. 
77. Carrella S, Barbato S, D'Agostino Y, Salierno FG, Manfredi A, Banfi S, et al TGF-beta controls miR-181/ERK regulatory network during retinal axon specification and growth. PLoS One. 2015;10(12):e0144129. https://doi.org/1 0.1371/journal.pone.0144129.

78. Helwak A, Kudla G, Dudnakova T, Tollervey D. Mapping the human miRNA interactome by CLASH reveals frequent noncanonical binding. Cell. 2013; 153(3):654-65. https://doi.org/10.1016/j.cell.2013.03.043.

79. Jalali S, Bhartiya D, Lalwani MK, Sivasubbu S, Scaria V. Systematic transcriptome wide analysis of IncRNA-miRNA interactions. PLoS One. 2013; 8(2):e53823. https://doi.org/10.1371/journal.pone.0053823.

80. Li JH, Liu S, Zhou H, Qu LH, Yang JH. starBase v2.0: decoding miRNA-ceRNA, miRNA-ncRNA and protein-RNA interaction networks from large-scale CLIPSeq data. Nucleic Acids Res. 2014;42(Database issue):D92-7. https://doi.org/1 0.1093/nar/gkt1248.

81. Paraskevopoulou MD, Georgakilas G, Kostoulas N, Reczko M, Maragkakis M, Dalamagas TM, et al. DIANA-LncBase: experimentally verified and computationally predicted microRNA targets on long non-coding RNAs. Nucleic Acids Res. 2013;41(Database issue):D239-45. https://doi.org/10.1093/ nar/gks1246.

82. Schug J, McKenna LB, Walton G, Hand N, Mukherjee S, Essuman K, et al. Dynamic recruitment of microRNAs to their mRNA targets in the regenerating liver. BMC Genomics. 2013;14(1):264. https://doi.org/10.1186/14 71-2164-14-264

83. Ziu M, Fletcher L, Savage JG, Jimenez DF, Digicaylioglu M, Bartanusz V. Spatial and temporal expression levels of specific microRNAs in a spinal cord injury mouse model and their relationship to the duration of compression. Spine J. 2014;14(2):353-60. https://doi.org/10.1016/j.spinee.2 013.08.015.

84. O'Brien J, Hayder H, Zayed Y, Peng C. Overview of MicroRNA Biogenesis, Mechanisms of Actions, and Circulation. Front Endocrinol (Lausanne). 2018; 9:402

85. Stavast CJ, Erkeland SJ. The Non-Canonical Aspects of MicroRNAs: Many Roads to Gene Regulation. Cells. 2019;8(11):1465.

86. Edwards AO, Ritter R 3rd, Abel KJ, Manning A, Panhuysen C, Farrer LA Complement factor $\mathrm{H}$ polymorphism and age-related macular degeneration. Science. 2005;308(5720):421-4. https://doi.org/10.1126/ science.1110189.

87. Hageman GS, Anderson DH, Johnson LV, Hancox LS, Taiber AJ, Hardisty LI, et al. A common haplotype in the complement regulatory gene factor $\mathrm{H}$ (HF1/CFH) predisposes individuals to age-related macular degeneration. Proc Natl Acad Sci U S A. 2005;102(20):7227-32. https://doi.org/10.1073/pna S.0501536102.

88. Haines JL, Hauser MA, Schmidt S, Scott WK, Olson LM, Gallins P, et al. Complement factor $\mathrm{H}$ variant increases the risk of age-related macular degeneration. Science. 2005;308(5720):419-21. https://doi.org/10.1126/ science.1110359.

89. Klein RJ, Zeiss C, Chew EY, Tsai JY, Sackler RS, Haynes C, et al. Complement factor $\mathrm{H}$ polymorphism in age-related macular degeneration. Science. 2005; 308(5720):385-9. https://doi.org/10.1126/science.1109557.

90. Ha M, Kim VN. Regulation of microRNA biogenesis. Nat Rev Mol Cell Biol. 2014;15(8):509-24. https://doi.org/10.1038/nrm3838.

91. Chen X, Shen L, Chou HH. MicroRNA-target binding structures mimic microRNA duplex structures in humans. PLoS One. 2014;9(2):e88806. https:// doi.org/10.1371/journal.pone.0088806.

92. Nigita G, Acunzo M, Romano G, Veneziano D, Lagana A, Vitiello M, et al. microRNA editing in seed region aligns with cellular changes in hypoxic conditions. Nucleic Acids Res. 2016;44(13):6298-308. https://doi.org/10.1093/ nar/gkw532.

93. Prada I, Gabrielli M, Turola E, lorio A, D'Arrigo G, Parolisi R, et al. Glia-toneuron transfer of miRNAs via extracellular vesicles: a new mechanism underlying inflammation-induced synaptic alterations. Acta Neuropathol. 2018;135(4):529-50. https://doi.org/10.1007/s00401-017-1803-x.

94. Thomas KT, Gross C, Bassell GJ. microRNAs Sculpt Neuronal Communication in a Tight Balance That Is Lost in Neurological Disease. Front Mol Neurosci. 2018;11:455

95. Boudreau RL, Jiang P, Gilmore BL, Spengler RM, Tirabassi R, Nelson JA, et al Transcriptome-wide discovery of microRNA binding sites in human brain. Neuron. 2014;81(2):294-305. https://doi.org/10.1016/j.neuron.2013.10.062.

96. Didiano D, Hobert O. Perfect seed pairing is not a generally reliable predictor for miRNA-target interactions. Nat Struct Mol Biol. 2006;13(9):84951. https://doi.org/10.1038/nsmb1138.
97. Tay Y, Zhang J, Thomson AM, Lim B, Rigoutsos I. MicroRNAs to Nanog, Oct4 and Sox2 coding regions modulate embryonic stem cell differentiation. Nature. 2008;455(7216):1124-8. https://doi.org/10.1038/nature07299.

98. Vella MC, Choi EY, Lin SY, Reinert K, Slack FJ. The C. Elegans microRNA let-7 binds to imperfect let-7 complementary sites from the lin-41 3'UTR. Genes Dev. 2004;18(2):132-7. https://doi.org/10.1101/gad.1165404.

\section{Publisher's Note}

Springer Nature remains neutral with regard to jurisdictional claims in published maps and institutional affiliations.
Ready to submit your research? Choose BMC and benefit from:

- fast, convenient online submission

- thorough peer review by experienced researchers in your field

- rapid publication on acceptance

- support for research data, including large and complex data types

- gold Open Access which fosters wider collaboration and increased citations

- maximum visibility for your research: over $100 \mathrm{M}$ website views per year

At BMC, research is always in progress.

Learn more biomedcentral.com/submissions 


\section{University Library}

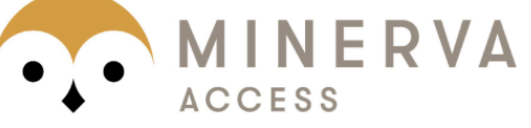

A gateway to Melbourne's research publications

Minerva Access is the Institutional Repository of The University of Melbourne

\section{Author/s:}

Chu-Tan, JA;Cioanca, AV;Feng, Z-P;Wooff, Y;Schumann, U;Aggio-Bruce, R;Patel, H;Rutar, M;Hannan, K;Panov, K;Provis, J;Natoli, R

Title:

Functional microRNA targetome undergoes degeneration-induced shift in the retina

Date:

2021-08-31

\section{Citation:}

Chu-Tan, J. A., Cioanca, A. V., Feng, Z. -P., Wooff, Y., Schumann, U., Aggio-Bruce, R., Patel, H., Rutar, M., Hannan, K., Panov, K., Provis, J. \& Natoli, R. (2021). Functional microRNA targetome undergoes degeneration-induced shift in the retina. MOLECULAR NEURODEGENERATION, 16 (1), https://doi.org/10.1186/s13024-021-00478-9.

Persistent Link:

http://hdl.handle.net/11343/296936

License:

CC BY 